\title{
Assessment of the heterogeneity of hydraulic properties in gravelly outwash plains: a regionally scaled sedimentological analysis in the Munich gravel plain, Germany
}

\author{
Markus Theel $^{1}$ • Peter Huggenberger ${ }^{2} \cdot$ Kai Zosseder $^{1}$ \\ Received: 22 October 2019 / Accepted: 20 June 2020 / Published online: 11 August 2020 \\ (C) The Author(s) 2020
}

\begin{abstract}
The favorable overall conditions for the utilization of groundwater in fluvioglacial aquifers are impacted by significant heterogeneity in the hydraulic conductivity, which is related to small-scale facies changes. Knowledge of the spatial distribution of hydraulically relevant hydrofacies types (HF-types), derived by sedimentological analysis, helps to determine the hydraulic conductivity distribution and thus contribute to understanding the hydraulic dynamics in fluvioglacial aquifers. In particular, the HF-type "open framework gravel (OW)", which occurs with the HF-type "bimodal gravel (BM)" in BM/OW couplings, has an intrinsically high hydraulic conductivity and significantly impacts hydrogeological challenges such as planning excavation-pit drainage or the prognosis of plumes. The present study investigates the properties and spatial occurrence of HF-types in fluvioglacial deposits at regional scale to derive spatial distribution trends of HF-types, by analyzing 12 gravel pits in the Munich gravel plain (southern Germany) as analogues for outwash plains. The results are compared to the reevaluation of 542 pumping tests. Analysis of the HF-types and the pumping test data shows similar small-scale heterogeneities of the hydraulic conductivity, superimposing large-scale trends. High-permeability BM/OW couples and their dependence on recognizable discharge types in the sedimentary deposits explain sharp-bounded small-scale heterogeneities in the hydraulic conductivity distribution from $9.1 \times 10^{-3}$ to $2.2 \times 10^{-4} \mathrm{~m} / \mathrm{s}$. It is also shown that high values of hydraulic conductivity can be interpolated on shorter distance compared to lower values. While the results of the HF-analysis can be transferred to other fluvioglacial settings (e.g. braided rivers), regional trends must be examined with respect to the surrounding topography.
\end{abstract}

Keywords Heterogeneity $\cdot$ Unconsolidated sediments $\cdot$ Scale effects $\cdot$ Equipment/field techniques $\cdot$ Hydraulic properties

\section{Introduction}

Gravelly outwash plains often contain large, continuous, shallow, sedimentary aquifers. These aquifers represent important natural and rechargeable groundwater resources, especially for the settlements built on them. The high-volume groundwater flow associated with gravelly outwash plains, facilitated by a generally high hydraulic conductivity, provides optimal water-

Markus Theel

m.theel@tum.de

1 Department of Civil, Geo, and Environmental Engineering, Technical University of Munich, Arcisstr. 21, D-80333 Munich, Germany

2 Department of Environmental Sciences, University of Basel, CH-4056 Basel, Switzerland supply conditions for domestic, agricultural and industrial purposes, and for use in shallow geothermal energy generation (e.g. Böttcher et al. 2019). However, groundwater management can be further enhanced by filling the gap of knowledge on the heterogeneity of hydraulic conductivity in the aquifer (Slomka et al. 2019). In particular, the distribution of highly permeable sediments and their connectivity control groundwater hydraulics and thus the transport dynamics in the groundwater body (Sanchez-Vila and Fernàndez-Garcia 2016).

To overcome this shortfall, knowledge about the links between the sediment units and hydraulic properties, as well as their spatial distribution, has led to more attention being paid to sedimentology in hydrogeological applications during the last few years (Fogg and Zhang 2016). It is basically understood that a large grain size, a high degree of rounding, and a good degree of sorting have a positive effect on the hydraulic conductivity of a sediment compared to a poorly sorted, very fine-grained sediment (Fetter 2001). Building on this 
knowledge, researchers have begun to classify sediments into hydrofacies types (HF-types) based on their sedimentological composition and their derivable hydraulic properties (Miall 2006). In fluvioglacial sediments like glacial outwash plains, highly permeable sediments are represented by the HF-type of pure open framework gravels (OW gravels). They are deposited alternately in combination with the HF-type of bimodal gravels (BM gravels), building BM/OW couplets in trough fillings (Jussel et al. 1994; Stauffer 2007; Vienken et al. 2017). The hydraulic conductivity of BM/OW couplets is two orders of magnitude higher than the average hydraulic conductivity of the other fluvioglacial deposits (Klingbeil et al. 1999). Studies with tracers showed that even if the highly permeable gravel only accounts for less than $2 \%$ of the sediments in the aquifer, it still holds $98 \%$ of the groundwater flow (Dann et al. 2008). In addition to the high groundwater flow rates, BM/OW couplets strongly affect advective mixing (Huber and Huggenberger 2016; Bennett et al. 2017). This underlines the importance of assessing the spatial distribution and size of HF-types, especially of the BM/OW couplet HFtype, within a fluvioglacial deposit environment, to explain the heterogeneity of the hydraulic conditions and to improve groundwater management and transport prognosis.

To be able to better represent the heterogeneity of an aquifer, knowledge of the distribution and size of HF-types is of great importance. HF-types of small size can cause strong local differences, whereas larger structures represent homogeneous conditions on a local scale. In order to improve the prediction of groundwater flow paths, the implementation of HF-type distributions in stochastic models has already been successfully carried out on small-scale case studies (Huggenberger and Regli 2006; Zappa et al. 2006; Comunian et al. 2011; Bayer et al. 2015). With the possibility of using large data sets, which are nowadays often collated in state databases, regional models are developed to better understand groundwater hydraulics (Huggenberger and Epting 2011; Bianchi et al. 2015; Kearsey et al. 2015; Slomka et al. 2019). As the model scale increases, stationarity becomes an important factor for realistic simulations in stochastic modeling (Bakshevskaya and Pozdnyakov 2013; Pyrcz and Deutsch 2014). In large gravel plains, nonstationary conditions can be caused by altered deposition processes, leading to spatially horizontal or vertical trends in the composition and extent of HF-types. The spatial trend represents spatial changes in the occurrence and shape of this facies within an aquifer and describes herewith changes in the prevailing hydraulic conductivity heterogeneity.

Regarding deposition in outwash plains, two types of (opposite) trends can be identified, on different scales, which reflect the composition of the HF-types and thus the spatial distribution of hydraulic conductivity. On the one hand, a large-scale shift from coarse-grained gravel in proximal areas to a sand-dominated pattern in distal areas is mostly described in modern gravelly outwash plain models (McDonald and Banerjee 1971; Boothroyd and Ashley 1975). A separation between "upper sandar" and "lower sandar", like in alluvial fans, is often presumed and accompanied by a shift in facies distribution (Górska-Zabielska 2008; Zhu et al. 2017). In a braid plain in Poland, a subdivision of four different proximal, coarse-grained facies packs ( $\mathrm{P} 1-4)$ and four distal, finergrained facies packs (D1-4) could be identified (Zielinski and van Loon 2003). Further studies see three zonations due to facies distribution in outwash plains: in the proximal, medial and distal area. Such a noticeable change in the composition of HF-types must be directly reflected in the regional trend of hydraulic conductivity distribution. According to Bowman (2019), the highest conductivity is to be expected in the medial area, while the values in the proximal and distal area decrease slightly.

On the other hand, reference is often made to the smallscale dependence of the predominant discharge system on the arrangement of the HF-types (Best and Fielding 2019). Heinz et al. (2003) indicated three different discharge types that can be found in fluvioglacial deposit areas, whose occurrence strongly influence the hydraulic conductivity. The sediments of the main discharge type are deposited on stable channels, have high preservation potential in the sedimentary record due to the low topographic level, and contain highly permeable HF-types (Siegenthaler et al. 1993; Huber and Huggenberger 2015). In the intermediate discharge type, channel stability decreases and the discharge system is more braided. Temporary, large discharge events can lead to a morphological change and the complete redesign of the drainage network. In the minor discharge type, deposition occurs mainly during large flood events and the deposits consist of mostly poorly sorted sediments. Most of the poorly sorted sediments build ground at topologically higher levels, so that only small gullies originate, with low discharge, and they have a low preservation potential.

This study was designed based on this knowledge, with the objective to describe the characteristics and distribution of HFtypes and their underlying regional trends in the shaping and arrangement in fluvioglacial outwash plains, and to use this information for the characterization of their spatial hydraulic conductivity heterogeneity. In particular, the highly permeable BM/OW couplets pose special challenges in the hydrogeological context of fluvioglacial aquifers such as dewatering in excavation pits, groundwater extraction, or the design of geothermal plants. These challenges are, for instance, noticed in the presented case study, the Munich gravel plain (MGP) in southeastern Germany. The MGP is a large glacial outwash plain, which presents challenges especially in the city of Munich, where a lot of groundwater users are located. Because of the significant effects of HF-type on the hydraulic dynamics, this study focuses on the occurrence and correlation lengths of $\mathrm{BM} / \mathrm{OW}$ couplets in the fluvioglacial deposits. For this purpose, 12 outcrops in the MGP were investigated. From the knowledge gained on the composition and size of the HF-types there, the influences on the hydraulic conductivity and 
their distribution in an outwash plain are determined. The conclusions drawn from the field work were then compared with a large data set derived from pumping tests.

\section{Project area}

The case study area is located in southeastern Germany, in the northern Molasse Basin of the northern Alps, including the Munich metropolitan area. The MGP, which comprises Quaternary fluvioglacial deposits, is situated between the younger moraine landscape of the Weichsel (Wuermian) glaciation in the south, the remains of the older moraine landscape of the Saale (Riss) glaciation in the east and west, and the Neogene Tertiary hilly landscape in the north (Fig. 1). Extending from north to south over a distance (length) of about $50 \mathrm{~km}$ and from east to west over a width of $40 \mathrm{~km}$ (2000 $\mathrm{km}^{2}$ area), the MGP is one of the largest gravelly outwash plains in central Europe and forms a north-north-east running wedge (Kerl et al. 2012; Penck and Brückner 1909). The Quaternary sediment thickness decreases from more than $100 \mathrm{~m}$ on the southern edge of the MGP to just a few meters in the northern parts. The gradient of the ground surface is reduced from $12 \%$ at the south margin of the urban area of

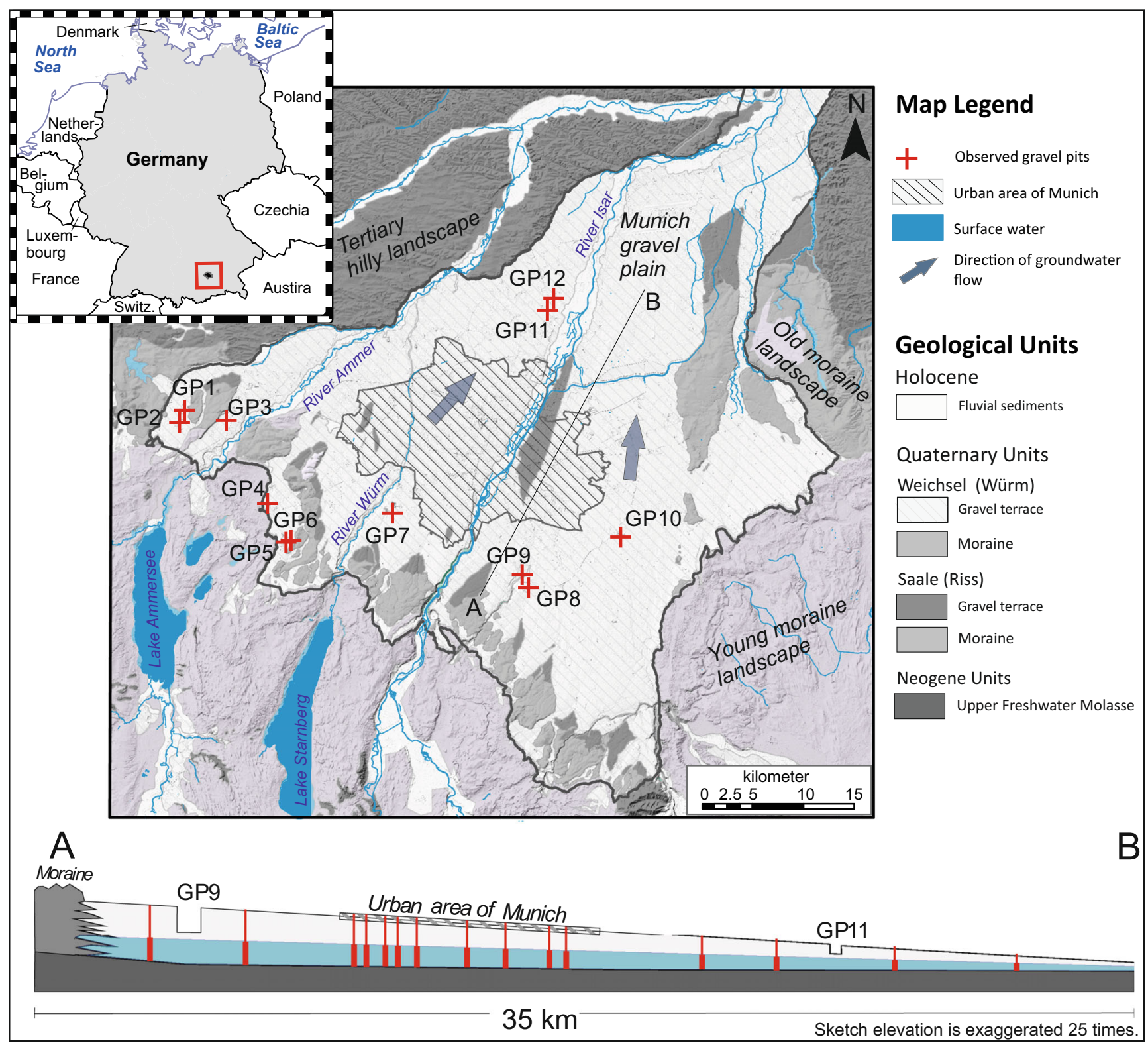

Fig. 1 Overview map of the geological setting of the Munich gravel plain on Germany. The geological map is simplified from Freudenberger and Schwerd (1996). The investigated gravel pits are marked with red crosses.
The schematic profile shows the architecture of the aquifer, as well as the unsaturated zone where the field observations were carried out and the monitoring wells (red) where the pumping tests were carried out 
Munich to $4-5 \%$ in the urban area, to finally approx. $2 \%$ in the area where the MGP is tangent to the Tertiary hilly landscape (Dohr and Gruban 1999).

In several glacial and interglacial periods during the Pleistocene, vast braided river systems deposited the sediments of the MGP, which today form a large gravelly sandy outwash plain (Penck and Brückner 1909; Doppler et al. 2011). During this process, several hundred meters of sediments were removed from the underlying Neogene Bavarian Upper Freshwater Molasses and large channel structures were formed in the base of the Quaternary sediments (Lemcke 1988; Albarrán-Ordás and Zosseder 2020). Most of the MGP is covered by the lower terrace gravel of the Weichsel (Wuermian) glaciation (Fig. 1). The lower terrace gravel is deposited in 12 gravel fans, which are mainly propagated from south to north, and were eastwardly derived by the Neogene Tertiary Hilly Landscape in the northern part of the MGP (Schaefer 1978). The higher terrace gravel of the Saale (Riss) glaciation has largely been eroded and relocated by the lower terrace gravel. Though rare, greater amounts of preserved high terrace gravel can be found in places like the eastern side of the Isar River in the urban area of Munich and on the southeastern part of the MGP. The older terrace gravel, which contains sediments from the Elster, Menap and Eburon glaciation, is scarcely preserved and only known due to data from drill sections next to the Quaternary base (Doppler et al. 2011).

The sediments of the MGP contain a vast, continuous, porous aquifer. The water level in this aquifer falls at a slightly lower angle (3\%o) than the mean slope of the ground surface in a northeasterly direction to the receiving water of the Isar River (Blasy 1974). This reduces both the groundwater thickness and the depth to the water level in a northerly direction. More than 3,000 groundwater utilizations have been approved in the MPG, including groundwater abstraction for industrial water, breweries, agriculture and gardening, and sustainable energy for heating or cooling buildings with near-surface geothermal energy schemes. These differ in size, number of wells and output. The permitted abstraction rate for the utilizations varies between 0.005 and $54,000 \mathrm{~m}^{3} /$ day and is on average $168 \mathrm{~m}^{3} /$ day. Some hydraulic conductivity studies were carried out due to the great importance of this aquifer for the region. From pumping tests carried out to establish the hydraulic conductivity of glacial gravel in the urban area, Exler (1967) determined a maximum of $4.0 \times 10^{-2} \mathrm{~m} / \mathrm{s}$ and a minimum of $5.0 \times$ $10^{-5} \mathrm{~m} / \mathrm{s}$ with a mean of $5 \times 10^{-3} \mathrm{~m} / \mathrm{s}$. For the evaluation of pumping tests in the south of Munich, a value range of $1.0 \times$ $10^{-2}-2.0 \times 10^{-4} \mathrm{~m} / \mathrm{s}$ is assumed (Gebhardt 1968). In the eastern part of the Munich gravel plain, 117 pumping tests were carried out (Schirm 1968). $54 \%$ of the values are in the range of $10^{-3} \mathrm{~m} / \mathrm{s}$, while $35 \%$ are in the range of $10^{-2} \mathrm{~m} / \mathrm{s}$. Only $2 \%$ of the collected pumping tests are in the range of $10^{-4} \mathrm{~m} / \mathrm{s}$ or $10^{-5} \mathrm{~m} / \mathrm{s}$. For the northwestern extension of the MGP, Grottenthaler (1980) specifies $1.0 \times 10^{-3}-9.0 \times 10^{-3} \mathrm{~m} / \mathrm{s}$ for the hydraulic conductivity.
While the hydraulic conductivity has been assessed and found to vary significantly in the deposits of the Munich gravel plain, studies on the facies description are rare. The sedimentary texture was rarely taken into account to explain the spatial hydraulic conductivity changes. In most cases, the sediments were described as a uniform gravel body. Only the BM/OW HF-type is mentioned in a few hydrogeological reports, but no concrete information is provided on the occurrence or characteristics of this facies type (Exler 1967; Mahrla 1982; Bauer et al. 2005). However, Zimniok (1967) was able to determine a maximum hydraulic conductivity of $2.0 \times 10^{-2} \mathrm{~m} / \mathrm{s}$ for BM/OW couplets (local name "Rollkieslagen"). For pure gravel (OW gravel) sampled near Munich Airport, a hydraulic conductivity of $1.0 \times$ $10^{-1} \mathrm{~m} / \mathrm{s}$ is assumed (Vogt 2006). A hydraulic conductivity value of $1.0 \times 10^{-5} \mathrm{~m} / \mathrm{s}$ can be determined for gravelly layers with a high proportion of fine material. However, different facies within the MGP are only considered in exceptional cases to describe the hydraulic heterogeneity. In almost every study, the sediments of the MGP are only described as a uniform gravel-sand mixture.

\section{Methods}

\section{Sedimentary investigations}

A hydrofacies (HF-type) analysis was performed in this study to gain a better understanding of the relationship between hydraulic conductivity and the sedimentary deposits of the MGP, as a representative area for outwash plains. In the literature, different classification systems are used for the subdivision into HF-types, most of them based on the concept of architectural element analysis for fluvial sediments according to Miall (1985). Siegenthaler et al. (1993) translated this concept to deposits of braided river systems, further developed by Klingbeil et al. (1999) into a frequently applied hydrofacies concept (Heinz and Aigner 2003b; Kostic and Aigner 2007; Bayer et al. 2015). The classification scheme used in this work is very closely based on the work of Klingbeil et al. (1999). The classification took place at the levels of the lithofacies, HF-types, and stacked HF-types (Fig. 2a). Lithofacies can be distinguished by sharp sedimentary boundaries and differentiations in grain composition (divided by dashed lines in Fig. 2). Based on the scheme after Klingbeil et al. (1999), the lithofacies types were combined into four HF-types (Gmm, $\mathrm{Gcm}, \mathrm{BM} / \mathrm{OW}$ couplets, and $\mathrm{S}$ ) with clear separable hydraulic properties. Figure 3 lists the four HF-types and the corresponding lithofacies types used in this work. Lithofacies belonging to a HF-type can vary slightly in grain composition (e.g. Gcm and Gcm,a in Fig. 3), but their hydraulic properties fluctuate in such a small range that they can be combined into one unit when considering HF-types. The stacked HF-types represent neighbouring HF-types of the identical HF-types, which are separated by sedimentological boundaries; 


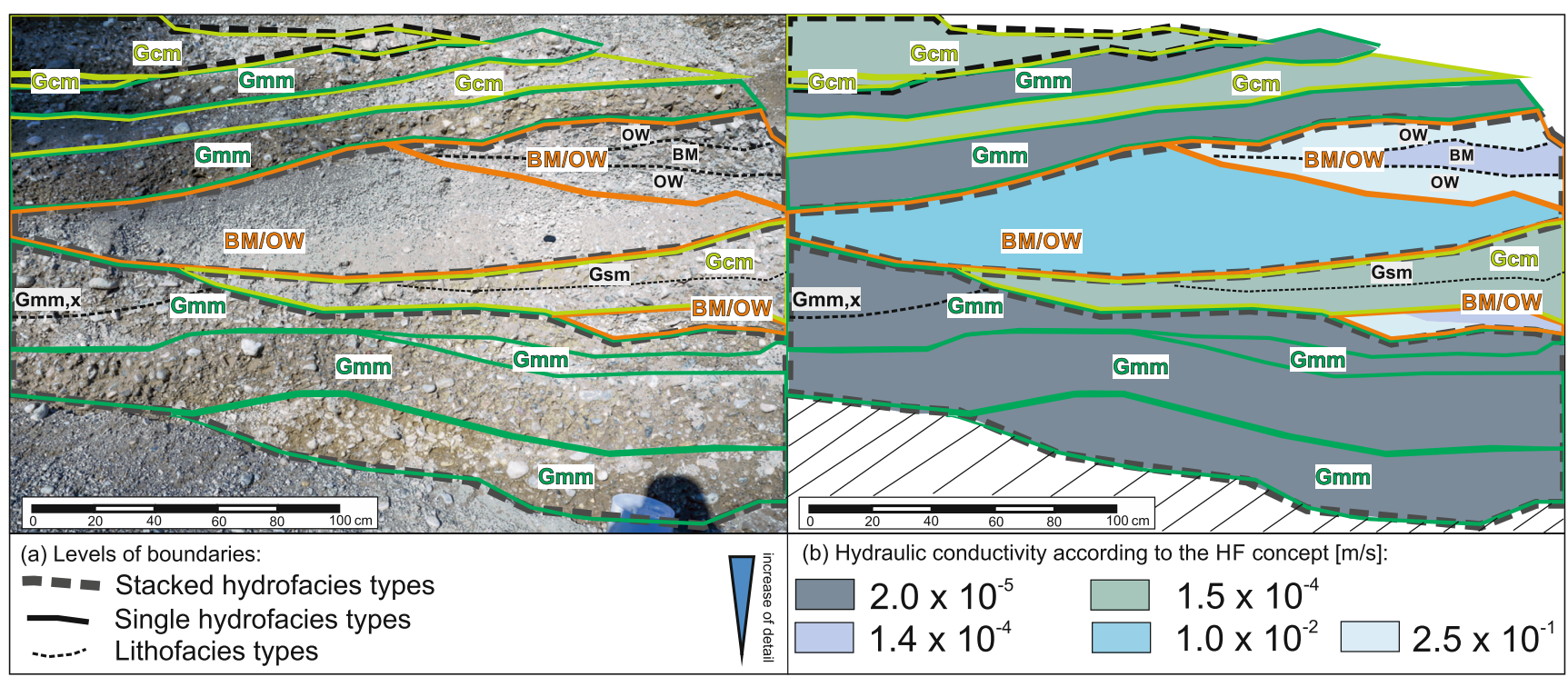

Fig. 2 Example of the outcrop investigation of three levels of detail in a gravel pit. a The interpretation of borders at the outcrop wall. b The transferred hydraulic properties after Jussel et al. (1994), which reflects the heterogeneity of the hydraulic conductivity in the fluvioglacial

deposits. The hydraulic properties of the BM/OW couplets were assigned here once at the level of the HF-type as a mean value (BM/OW couplet in the center of the picture) and once at the level of the lithofacies types (BM/OW couplets on the right margin of the picture)

however, they may be combined into one unit in case of hydraulically driven issues, as they represent a sediment body with the same hydraulic properties (Fig. 2b).

The occurrence and arrangement of the HF-types reflect their depositional conditions. The main difference of the HFtypes is the distinction between accretionary elements and cutand-fill elements (Heinz and Aigner 2003b; Huggenberger and Regli 2006).

Cut-and-fill-elements (CFE) are typically scour fillings with an erosive, concave, upward-shaped lower boundary, which are typically located in confluences of channels or in river bends (Ashmore 2017). Because of their low topography level in the channel during the sedimentation, CFE have a good chance to be preserved (Huber and Huggenberger 2015). CFE are mainly built up by the HF-type BM/OW. Strictly speaking, these are two HFtypes, consisting of bimodal gravel (BM) and the highly permeable, pure, open framework gravels (OW), actually both single types acting hydraulically very differently. However, as these types always appear together and are closely linked, they are treated mostly as one and with averaged hydraulic properties assigned (Fig. 2b). BM/OW couplets always show an alternating crossbedding with a fining-upward sequence (Huggenberger and Regli 2006). While the BM gravels exhibit a hydraulic conductivity of $1.4 \times 10^{-4} \mathrm{~m} / \mathrm{s}$ and a porosity of $27 \%$, in the OW gravels a hydraulic conductivity of $2.5 \times 10^{-1} \mathrm{~m} / \mathrm{s}$ and a porosity of $34.9 \%$ were determined (Klingbeil et al. 1999). For local or larger scale applications, only the mean value of $\mathrm{BM} / \mathrm{OW}$ couplets for the hydraulic conductivity is of interest. Jussel et al. (1994) indicate for the hydraulic conductivity of the aggregated BM/OW HFtype a value of $1.0 \times 10^{-2} \mathrm{~m} / \mathrm{s}$ (Fig. $2 \mathrm{~b}$ ).

The HF-type $\mathrm{S}$ symbolizes sand lenses. These can occur with crossbedded or horizontal internal layering. The lower edge is curved concave in accordance with the CFE. The sands are well sorted and consist predominantly only of middle sand (Fig. 3). The hydraulic conductivity of the sand amounts to $2.6 \times 10^{-4} \mathrm{~m} / \mathrm{s}$ and the porosity is $42.6 \%$ (Jussel et al. 1994).

Horizontally layered accretionary elements are built up by the HF-types $\mathrm{Gmm}$ and $\mathrm{Gcm}$. The matrix-rich gravels (HFtype $\mathrm{Gmm}$ ) are characterized by poor sorting and no imbrication (Todd 1989). In addition to gravel, this type often carries stones as well. Sand and fine material are often present in equal proportions. For Gmm, a hydraulic conductivity of $2.0 \times 10^{-5} \mathrm{~m} / \mathrm{s}$ and a porosity of $14 \%$ is given (Jussel et al. 1994). The clast-supported gravels (Gcm type) appear with a very low proportion of fines and sometimes show imbrication. The hydraulic conductivity is $1.5 \times 10^{-4} \mathrm{~m} / \mathrm{s}$ and the porosity $20 \%$ (Jussel et al. 1994). The most important lithofacies type of $\mathrm{Gcm}$ found in the MGP is the horizontal alternated $\mathrm{Gcm}$,a (Fig. 3). This lithofacies type is characterized by interbedding pure OW gravel. Unlike in BM/OW couplets, the OW layers in the lithofacies type $\mathrm{Gcm}$, a can be $2-7 \mathrm{~cm}$ thick and several meters long. It is not known for certain how strongly the OW layer of this subtype influences the groundwater flow, particularly because the OW layers do not seem to be connected.

The outcrop investigations to derive HF-type geometry and occurrence for outwash plains, describing hydraulic conductivity heterogeneity, were conducted in 12 gravel pits in the MGP (Fig. 1). All outcrops are located in the lower terrace gravel of the Wuermian glaciation. Due to the dense population in the urban area of Munich and the decreasing depth to the water table, outcrops in the middle and northern parts of 


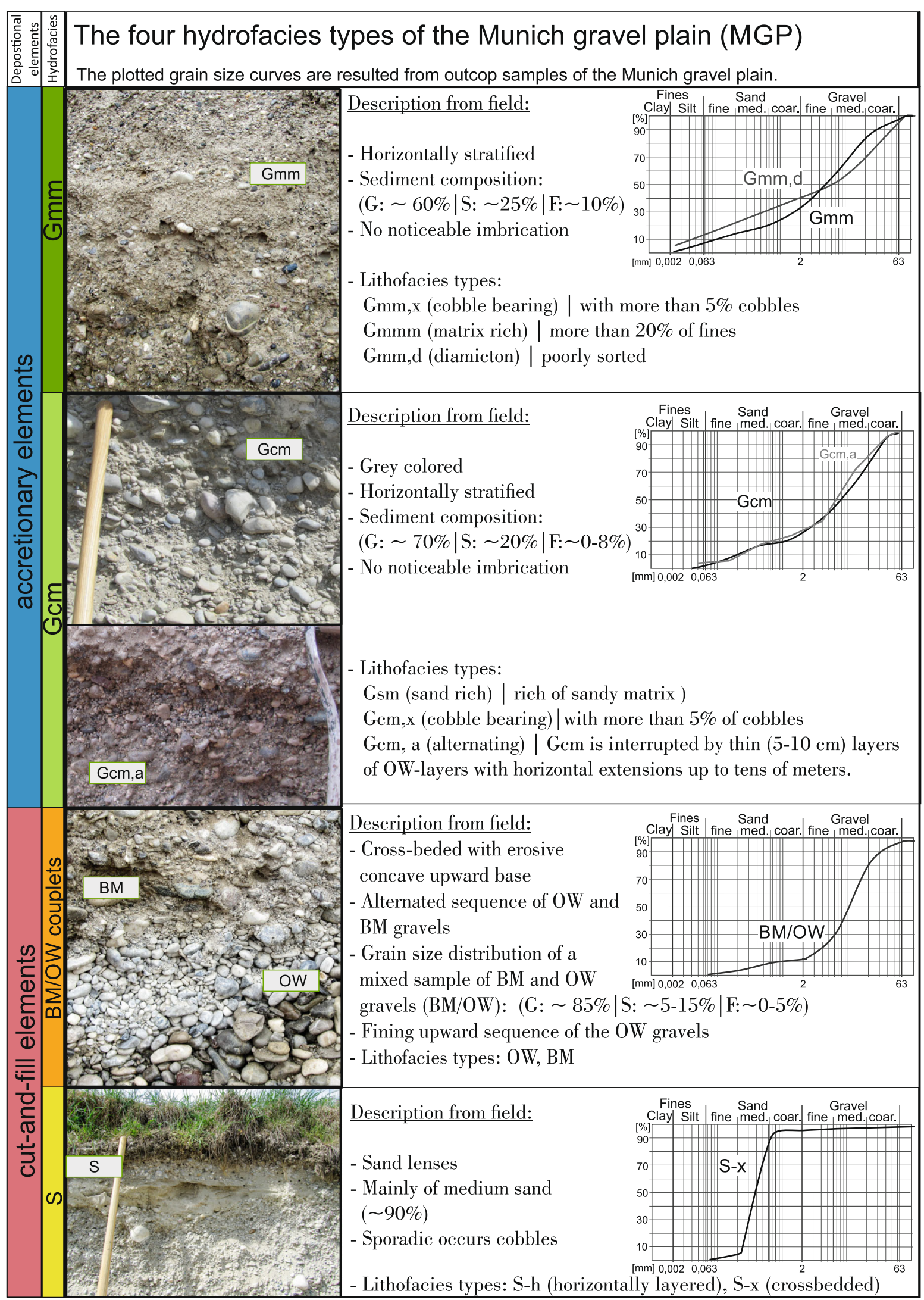

Fig. 3 Hydrofacies types found in the Munich gravel plain and their appropriate lithofacies types 
the MGP are rare. The outcrop analyses were executed using georeferenced photos from unweathered outcrop walls parallel and perpendicular to the palaeoflow direction. Figure 2 shows a detailed excerpt of a classified outcrop wall, which also shows the small-scale changes in hydraulic conductivity. This sedimentological study focuses on the distribution of the HF-types and on the geometries of the stacked HF-types. The proportion ratio and the shape of each HF-type were measured with ArcGIS (ESRI; Klingbeil et al. 1999). The length measurement could be made in three spatial directions: on the horizontal level parallel (x_par) and perpendicular (x_per) to the expected palaeoflow direction, and in the vertical direction (z). For a better understanding of the whole outcrop, the analyzed outcrop pictures were placed in spatial relation with the software SKUA (Paradigm).

\section{Evaluation of pumping tests}

For the evaluation of pumping tests, the reports on pumping tests archived in the responsible water authority offices were collected, digitized and analysed. The individual reports were checked for completeness and classified according to a quality scheme regarding data quality and plausibility. In order for the pumping tests to be included in the evaluation, it had to be ensured that the information on aquifer thickness and well construction data were complete. The temporal change in the water level had to be documented in appropriate time steps, depending on the evaluation procedure. Based on the quality of the drawdown diagrams and tables, the hydraulic conductivity was determined on the basis of each pumping test report using up to three different analysis methods: the drawdown was evaluated with Theis (with Jacob correction; Theis 1935), the steady state after Dupuit-Thiem (Thiem 1906) and the recovery with the formula of Theis and Jacob (Theis 1935). All methods were chosen or adapted to be valid for the large, continuous, unconstrained, porous aquifer of the MGP. To take the uncertainty and a bias of the pumping test into account, a schema was developed based on the choice of the respective evaluation method and the quality of the input data (Appendix), which provides a subdivision into three quality levels. The derived hydraulic conductivity values with a reasonable low uncertainty (quality level of 1 and 2) were used for further consideration. Each hydraulic conductivity value used in this paper provides the geometric mean of all hydraulic conductivity values obtained from one pumping test.

\section{Results}

\section{Evaluation of the pumping test in the MGP}

The evaluation of pumping test data led to a total of 542 pumping tests of sufficient quality. The pumping tests were distributed over large areas of the MGP, with a higher density in the urban area of Munich (Fig. 4a). By applying multiple evaluation methods and evaluating several pumping stages, up to ten values for the hydraulic conductivity at one single location were obtained from one pumping test report. It was found that the individual values for hydraulic conductivity derived from a report scatter by an average of $8 \%$ around the geometric mean. At a few wells there are reports of several independent pumping tests. The geometric mean values of the individual pumping tests deviate on average by $17 \%$ from the calculated geometric mean value of all pumping tests at each of these wells. A good value to describe the heterogeneity of the hydraulic conductivity in the aquifer is $\sigma_{\mathrm{lnK}}^{2}$, which is a third from the squared range between the max and min values in orders of magnitude (base 10) of measured hydraulic conductivity (Fogg and Zhang 2016). The hydraulic conductivity of the pumping tests was measured in the range of $2.0 \times 10^{-6}$ to $1.3 \times 10^{-1} \mathrm{~m} / \mathrm{s}$, which led to a high $\sigma^{2}$ lnK value of 8.33 . The histogram of the hydraulic mean values shows a right-skewed distribution around a geometric mean value of $5.9 \times 10^{-3} \mathrm{~m} / \mathrm{s}$ (Fig. 4d). $80 \%$ of all values were within the interval from $3.1 \times 10^{-5}$ to $2.5 \times 10^{-3} \mathrm{~m} / \mathrm{s}$. By applying multiple evaluation methods and evaluating several pumping stages, up to ten values for the hydraulic conductivity at one single location were obtained from one pumping test report. It was found that the individual values for hydraulic conductivity derived from a report scatter by an average of $8 \%$ around the geometric mean. At a few wells there are reports of several independent pumping tests. The geometric mean values of the individual pumping tests deviate on average by $17 \%$ from the calculated geometric mean value of all pumping tests at each of these wells.

In Fig. 4e, the evaluated pumping tests were clustered according to the distance to the former ice margin. The mean values vary between $7.2 \times 10^{-3}$ and $1.2 \times 10^{-2} \mathrm{~m} / \mathrm{s}$. A downfan-facing trend could not be detected. However, even in the evaluated pumping test data, large steps by two orders of magnitude can be observed at relatively short distances (300 m; Fig. 4b,c). In order to identify significant large-scale trends, the pumping test data were interpolated using the moving average method (Isaaks and Srivastava 1989). Although a large radius of $8 \mathrm{~km}$ was used for the interpolation step, regional differences can be detected (Fig. 4a). Slightly elevated hydraulic conductivity values are conspicuous in areas where topographic constrictions are present. This occurs in the southernmost MGP, where the MGP is still constrained by moraine hills, and in the northernmost MGP, where it intersects the Tertiary hilly landscape. However, even these differences on a regional scale are very small compared to the small-scale heterogeneity.

\section{Appearance of HF-types in the MGP}

All sediments in the observed outcrops in the MGP can be classified as braided river gravel bodies within the meaning of 


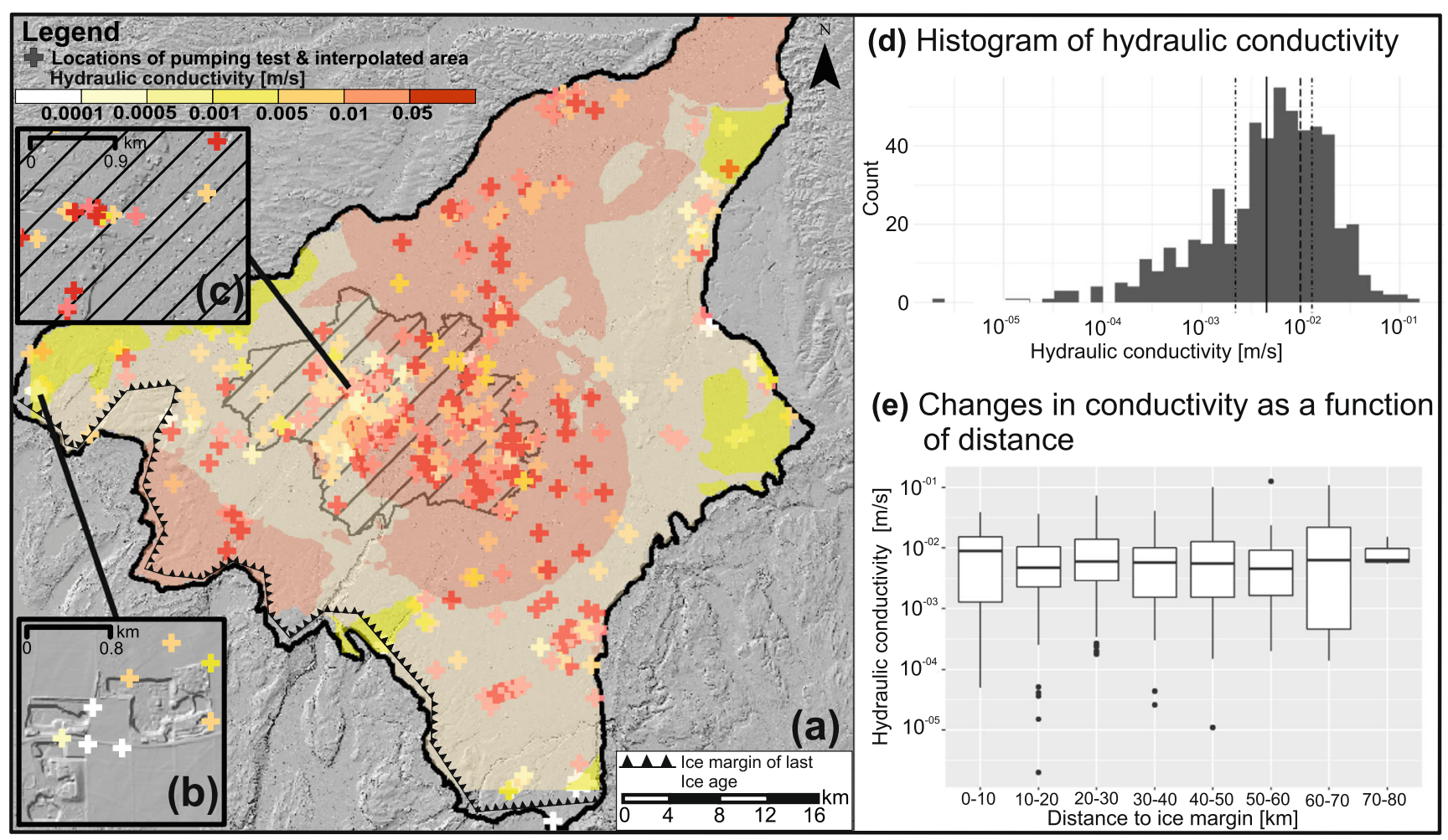

Fig. 4 a Distribution of hydraulic conductivity values in the MGP, created by moving average interpolation. b-c Represent close-ups showing the strong heterogeneity of the hydraulic conductivity on a small scale. The distribution of the individual hydraulic conductivity values from the pumping tests is shown as: $\mathbf{d}$ a histogram for the entire Munich gravel plain and $\mathbf{e}$ as a function of the distance to the ice edge during the last Ice Age
Heinz and Aigner (2003a). The only exception is the lower sediment in outcrop GP5. This one, characterized by massive, poorly sorted, kind of diamicton lithofacies of type $\mathrm{Gmm}, \mathrm{d}$, is designated as material from the ice contact zone.

The braided river gravel bodies are built up by accretionary and cut-and-fill elements (CFE). Overall, CFE comprise onefifth of the observed sediments, while around $80 \%$ of the investigated sediments are accretionary elements. The areal proportion analysis of the HF-types in the gravel pits reveals that the horizontally layered HF-types Gcm (47.4\%) and Gmm (32.8\%) dominate in the MGP, corresponding to the proportion of accretionary elements. The CFE mainly consist of $\mathrm{BM} / \mathrm{OW}$ gravel (17.9\%) and S-x (1.8\%). Multiplying the percentages of the individual HF-types mapped in the outcrops by the measured hydraulic conductivity values of each HF-type, an average value of $3.7 \times 10^{-3} \mathrm{~m} / \mathrm{s}$ can be calculated for the entire sediments of the MGP.

\section{Discharge types}

It is, however, obvious that the distribution and the size in which the HF-types appear vary markedly from outcrop to outcrop and within one outcrop. Due to the arrangement of the individual HF-types in the outcrops, the sediments could be assigned to the three different discharge types within the meaning of Heinz et al. (2003), which indicate different prevailing drainage networks during the deposition (Fig. 5). In the MGP, the three discharge types exhibit the following characteristics of the main, intermediate or minor discharge types.

The main discharge type is equivalent to the active zone of a modern braided river system. In the sedimentary record, this type is characterized by sharp, mostly trough-shaped boundaries, which indicate locally strong erosive processes. With one exception, all observations of this discharge type are investigated on outcrop walls perpendicular to the paleoflow direction. The lengths of the main discharge type observed in the MGP in this direction are 20-50 m, with a vertical thickness of 5-7 m. In the direction parallel to the palaeoflow, no reliable statements could be made. Only $11 \%$ of all investigated sediments could be assigned to the main discharge type. The sediments are characterized by a high proportion of crossbedded BM/OW couplets, which are often stacked and build complexes. This HF-type also contributes to good hydraulic conductivity in main discharge types, although the effect is not as strong as the BM/OW couplets. Beside the BM/ OW couplets, one can also find the HF-types Gcm, which can occur partly crossbedded, partly parallel layered. Parallel layered Gcm types often occur in the main discharge type in the form of the lithofacies types $\mathrm{Gcm}$, a, containing highly permeable OW layers as well. In some outcrops, large sand lenses 


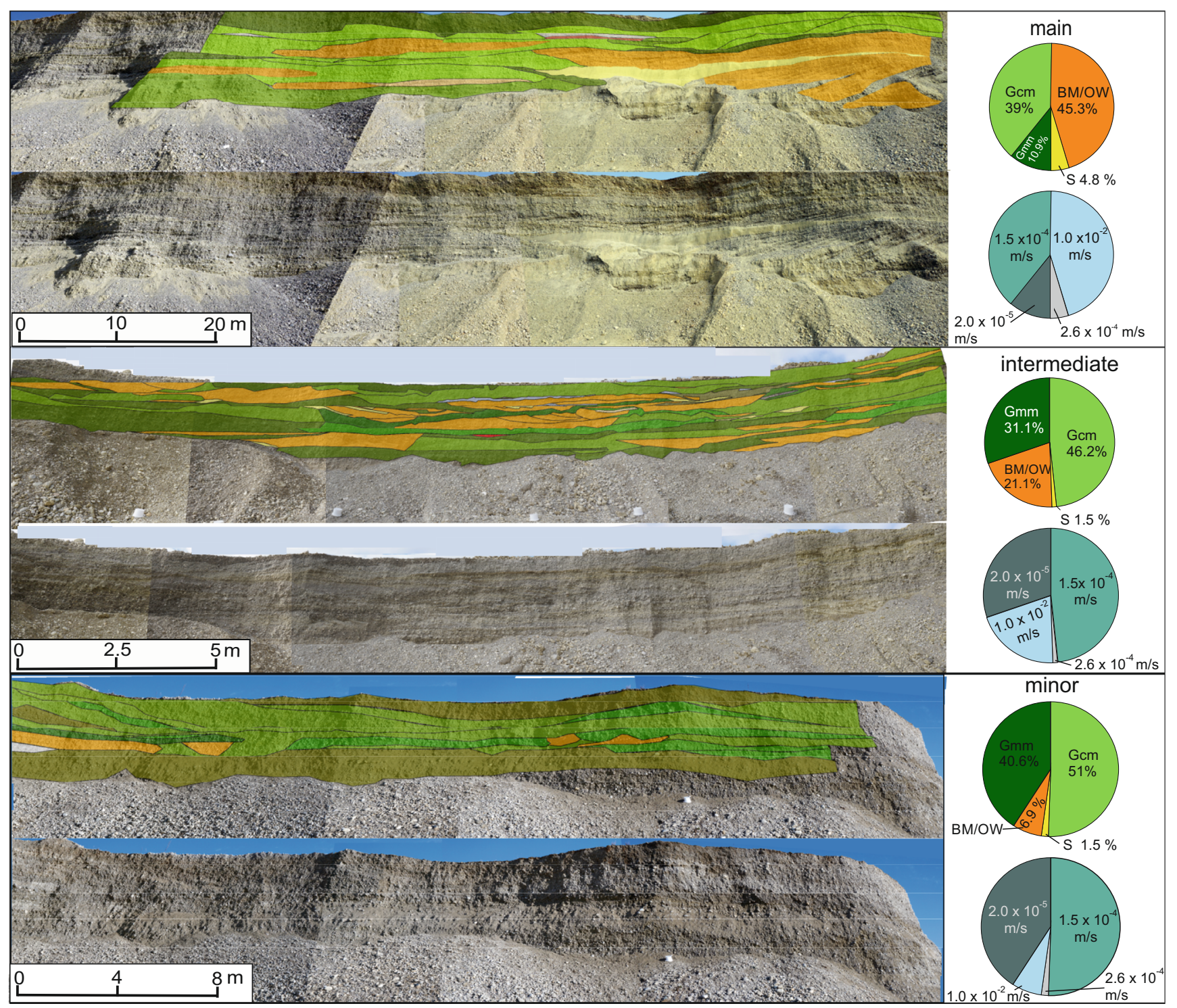

Fig. 5 Photographs and sketches of the three discharge types: main, intermediate and minor. For each discharge type, two pie charts are shown: the upper pie chart shows the average distribution of the HFtypes within the respective discharge type, and the lower pie chart shows the resulting composition of the hydraulic conductivity field according to the parameterization of Jussel et al. (1994) in the respective discharge type
(HF-type S), which superimpose the BM/OW, could be found or are interbedded between two packets of BM/OW couplet and point out changing conditions in the outflow strength. In order to estimate the effects of this discharge type on hydraulic conductivity, the average proportion of HF-types was calculated with the corresponding values of the hydraulic conductivity. The estimated value of $9.1 \times 10^{-3} \mathrm{~m} / \mathrm{s}$ indicates the positive effect of the deposition condition on hydraulic conductivity. Especially in these discharge types, it has to be considered that the connection of the highly permeable BM/ OW couplets has an additional positive effect.

In the MGP the most frequently encountered discharge type is the intermediate discharge type (47\%). The intermediate zone is composed of accretionary elements (Gcm, Gmm), which are often interrupted by BM/OW couplets or sand lenses. In this case, the BM/OW couplets are not connected and only rarely stacked. This leads to a more frequent occurrence of the HF-types $\mathrm{Gcm} / \mathrm{Gmm}$ in the sediments of the discharge type and to a lower proportion of the BM/OW couplets of $21.1 \%$ (Fig. 5). Overall, in the intermediate discharge type are the most frequent transitions from highly permeable BM/OW to the lower permeability HF-types Gmm and Gcm, resulting in sharp discontinuities of hydraulic conductivity in a very small space. This rapid change of facies between good and poorly conducting HF-types results in an average value of $4.3 \times 10^{-3} \mathrm{~m} / \mathrm{s}$ for this discharge type. 
The sediments of this minor discharge type indicate strong aggregation processes. These sediments are composed of large deposits of the $\mathrm{Gcm}$ and $\mathrm{Gmm}$ lithofacies, appearing as horizontally layered gravel sheets (Heinz et al. 2003). Due to the poor sorting process during deposition, these HFtypes exhibit a low hydraulic conductivity (Fig. 2b). Marks of a channelized drainage network are hardly found. BM/OW couplets, which occupy less than $10 \%$ of the sediments investigated, are predominantly singular and have similar correlation lengths, like the sediments of the intermediate discharge type. The calculated hydraulic conductivity value within these discharge types is $2.2 \times 10^{-4} \mathrm{~m} / \mathrm{s}$, which is low compared to other fluvioglacial sediments settings.

\section{Extensions of HF-types}

Since there is a large range in the hydraulic conductivity of some HF-types, the correlation lengths of the individual HFtypes are important in order to better grasp the heterogeneity of hydraulic parameters in the aquifer. HF-types with long correlation lengths indicate homogeneous aquifer material, whereas small-scale HF-types stand for frequent changes in hydraulic conductivity. Like the occurrence of the HF-types themselves, the distribution of the correlation length shows a slight dependence on the discharge types, although to a considerably reduced amount.

In the main discharge types, the $\mathrm{BM} / \mathrm{OW}$ couplets not only occur most frequently, but also form the largest bodies due to their stacking characteristics (GeoMean: x par: $12.0 \mathrm{~m}$, x_per: $6.3 \mathrm{~m}$, Table 1). In addition, in the topographically deeply incised main discharge type, the $\mathrm{BM} / \mathrm{OW}$ couplets are better preserved and have a higher thickness $(z: 1: 75 \mathrm{~m})$ than in intermediate or minor discharge types, where the thickness of HF-types generally remains less than $1 \mathrm{~m}$ (Fig. 6). The correlation lengths in the intermediate and minor discharge type are not distinguishable. In both discharge types, the BM/OW couplets show on average very small horizontal correlation lengths, which can, however, in exceptional cases be up to $30 \mathrm{~m}$. The relationships as described for $\mathrm{BM} / \mathrm{OW}$ couplets are also correct for the smaller occurring HF-type S.

The less permeable HF-types Gmm and Gcm, which belong to the depositional elements, follow no obvious dependence on the discharge types. In this case, there is no clear distinction in the length characteristics of the HF-types $\mathrm{Gcm}$ and $\mathrm{Gmm}$ in the minor or intermediate discharge type. Some HF-types of Gmm have horizontal lengths of up to $80 \mathrm{~m}$ (Table 1), although the measurement of larger lengths is usually restricted by the limited outcrop area. The thickness of the layers can reach 3-4 $\mathrm{m}$ independently of the discharge type, although the mean is approx. $1 \mathrm{~m}$. Similar distributions in the measured sizes are present for the HF-type Gcm (Table 1). What is striking, however, is that it can also reach a relatively large horizontal expansion in the main discharge type. This is based almost exclusively on the lithofacies type Gcm,a. This gravel, including thin OW gravel layers, occurs predominantly only in the main and rarely in the intermediate discharge type and can occur in large sizes (x_par: $\sim 50 \mathrm{~m}, \mathrm{x} \_$per: $\sim 25 \mathrm{~m}, z$ $\sim 3 \mathrm{~m}$ ). Other lithofacies types assigned to the HF-type

Table 1 Length of the hydrofacies types Gcm, Gmm and S sorted by corresponding depositional elements (DE). Shown as dependent on the orientation to the assumed palaeo-flow direction and the respective discharge type

\begin{tabular}{|c|c|c|c|c|c|c|c|c|c|c|c|}
\hline \multirow[t]{2}{*}{$\mathrm{DE}$} & \multirow[t]{2}{*}{ HF- type } & \multirow{2}{*}{$\begin{array}{l}\text { discharge } \\
\text { type }\end{array}$} & \multicolumn{3}{|c|}{ x_par } & \multicolumn{3}{|c|}{$\mathrm{x} \_$per } & \multicolumn{3}{|l|}{$z$} \\
\hline & & & $\begin{array}{l}\min \\
{[\mathrm{m}]}\end{array}$ & $\begin{array}{l}\text { geoMean } \\
{[\mathrm{m}]}\end{array}$ & $\begin{array}{l}\max \\
{[\mathrm{m}]}\end{array}$ & $\begin{array}{l}\min \\
{[\mathrm{m}]}\end{array}$ & $\begin{array}{l}\text { geoMean } \\
{[\mathrm{m}]}\end{array}$ & $\begin{array}{l}\max \\
{[\mathrm{m}]}\end{array}$ & $\begin{array}{l}\min \\
{[\mathrm{m}]}\end{array}$ & $\begin{array}{l}\text { geoMean } \\
{[\mathrm{m}]}\end{array}$ & $\begin{array}{l}\max \\
{[\mathrm{m}]}\end{array}$ \\
\hline \multirow{6}{*}{$\begin{array}{c}\text { Accretionary } \\
\text { elements }\end{array}$} & \multirow[t]{3}{*}{$\mathrm{Gcm}$} & Main & 7.2 & 25.9 & 52.7 & 2.2 & 7.3 & 25 & 0.8 & 1.75 & 3.6 \\
\hline & & Intermediate & 1.2 & 7.5 & 64.3 & 0.7 & 6.7 & 34 & 0.15 & 0.85 & 3.75 \\
\hline & & Minor & 0.6 & 6.1 & 33.6 & 0.5 & 8.7 & 71.3 & 0.05 & 0.65 & 3.15 \\
\hline & \multirow[t]{3}{*}{$\mathrm{Gmm}$} & Main & 0.7 & 2.3 & 7.4 & 3.4 & 10 & 22.2 & 0.3 & 0.75 & 2.25 \\
\hline & & Intermediate & 0.7 & 9.4 & 40.2 & 0.4 & 5.8 & 41.9 & 0.1 & 0.8 & 4 \\
\hline & & Minor & 0.6 & 6.5 & 50.9 & 1.1 & 10.2 & 83.2 & 0.1 & 0.8 & 3.85 \\
\hline \multirow[t]{6}{*}{ Cut-and-fill element } & \multirow[t]{3}{*}{$\mathrm{BM} / \mathrm{OW}$} & Main & 8.3 & 12.0 & 28 & 2.3 & 6.3 & 20.1 & 0.4 & 1.1 & 3.8 \\
\hline & & Intermediate & 0.4 & 2.3 & 24.3 & 0.5 & 2.5 & 22.0 & 0.05 & 0.3 & 2.8 \\
\hline & & Minor & 0.7 & 2.7 & 31.2 & 0.7 & 3.4 & 13.6 & 0.1 & 0.4 & 1.7 \\
\hline & \multirow[t]{3}{*}{$\mathrm{S}$} & Main & 1.3 & 5.2 & 28.4 & 2.6 & 2.6 & 2.6 & 0.25 & 0.4 & 2.9 \\
\hline & & Intermediate & 0.3 & 1.5 & 18.1 & 0.4 & 1.8 & 15.1 & 0.05 & 0.2 & 1.35 \\
\hline & & Minor & 0.6 & 1.8 & 9.7 & 0.2 & 2.1 & 21.8 & 0.1 & 0.3 & 1.2 \\
\hline
\end{tabular}




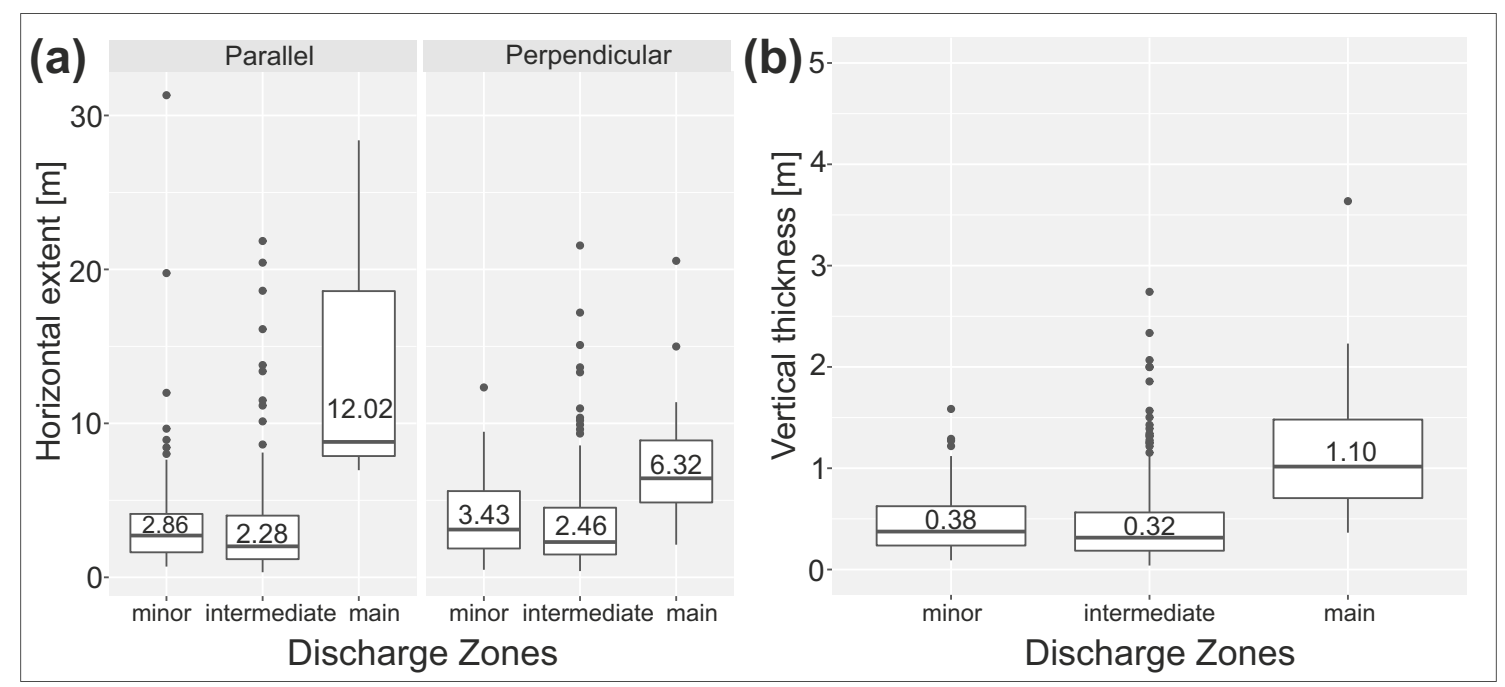

Fig. 6 Dimensions of stacked BM/OW couplets classified after their discharge types. The numbers represent the geometric mean of each dataset. a Horizontal extent of stacked BM/OW couplets. b Vertical thickness of stacked BM/OW couplets

Gcm occur in the main discharge type in considerably smaller sizes (x_par: $\sim 3 \mathrm{~m}$, x_per: $\sim 5 \mathrm{~m}, z \sim 0.6 \mathrm{~m}$ ).

In particular, the low thickness of the individual HFtypes shows strong differences in the hydraulic conductivity in the vertical profile. Due to the low spread of the main discharge type $(20-50 \mathrm{~m})$ compared to the other two $(>100 \mathrm{~m})$, it can be assumed that the higher hydraulic conductivity values have a smaller spatial correlation than the lower values.

\section{Regional trends}

Spatial distribution trends are relatively weakly pronounced in the MGP (Fig. 7a). Within the accretionary elements, a change to better sorted sediments can be observed with increasing distance to the former ice sheet margin. The $\mathrm{Gcm} / \mathrm{Gmm}$ ratio changes to a higher proportion of $\mathrm{Gcm}$. In the area proximal to the former ice sheet margin, the low-permeability matrix-supported Gmm

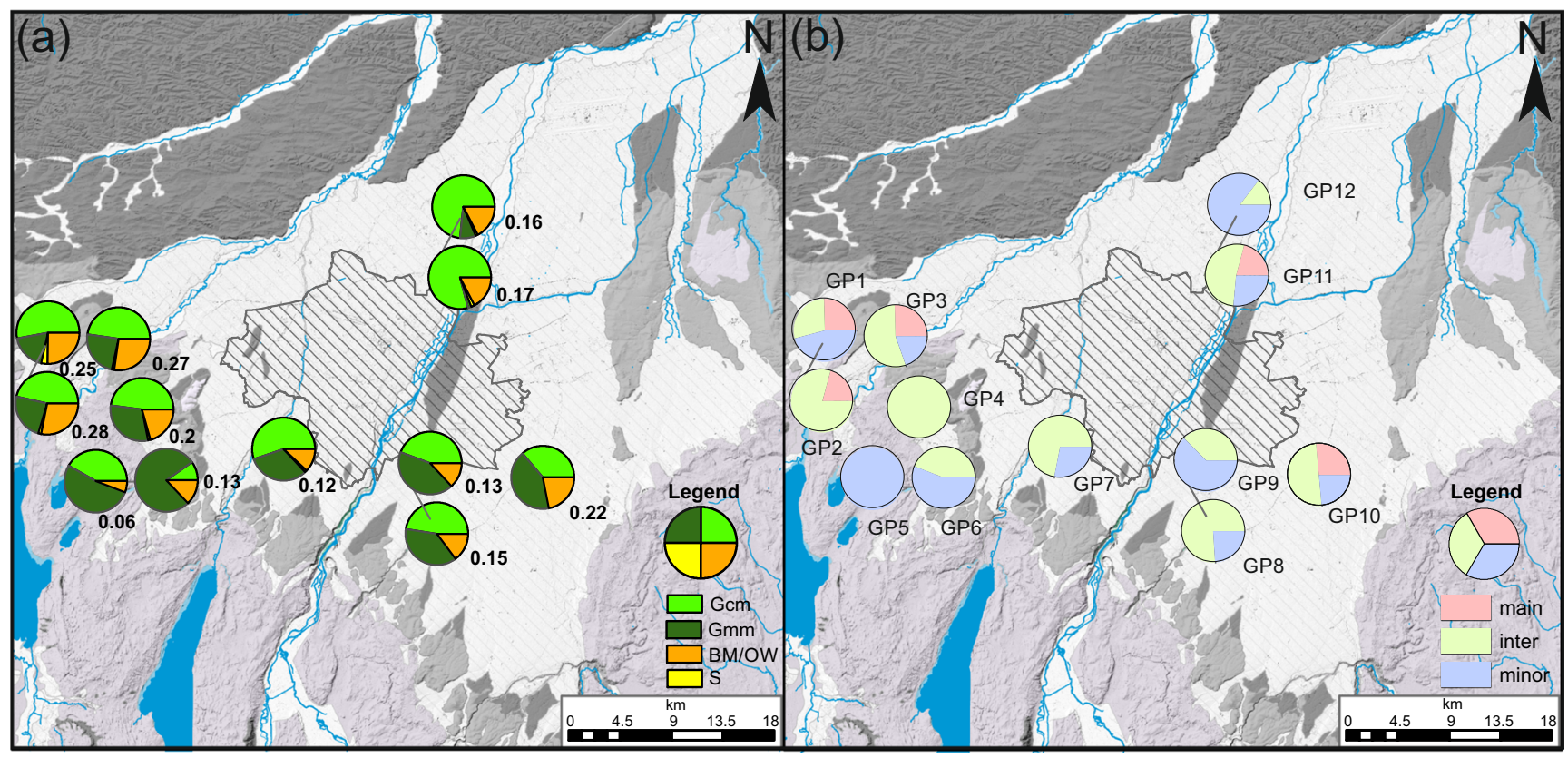

Fig. 7 a Distribution of hydrofacies types in all outcrops. The number stands for the proportion of BM/OW gravel in the outcrops. b Distribution of the various discharge types in all outcrops within the meaning of Heinz et al. (2003). The map in the background corresponds to the geological map in Fig. 1 
gravel comprises a large part of the investigated sediments (outcrop locations: GP5, GP6). Five to ten kilometers in the downcurrent direction, the ratio shifts in favor of the sandier lithofacies type $\mathrm{Gcm}$. In northern Munich, lithofacies type $\mathrm{Gcm}$ dominates within the accretionary elements. In these outcrops, the HF-type Gcm occurs frequently in the form of the lithofacies type Gsm. This lithofacies distinguishes itself from lithofacies type $\mathrm{Gcm}$ with a larger share of sandy matrix. The share of highly permeable BM/OW couplets is not subject to any spatial trend. As mentioned above, this is determined by the conditions during deposition (discharge type). In outcrops where the main discharge type was found, the proportion of BM/OW couplets is also higher (Fig. 7).

\section{Discussion}

\section{Estimation of the hydraulic conductivity distribution in fluvioglacial outwash plains and its limitations based on HF-analyses}

A hydraulic conductivity of $5.9 \times 10^{-3} \mathrm{~m} / \mathrm{s}$, geometrically averaged from 542 quality-checked pumping test data, describes the sediments of the MGP as highly permeable. Thereby a high heterogeneity of the evaluated $\sigma^{2} \operatorname{lnK}$ of 8.33 can be seen in the pumping tests, which is, according to Fogg and Zhang (2016), typical for high-energy sediments. The transfer from the hydraulic conductivity values according to Jussel et al. (1994) to the results of the HF-analysis yielded an averaged hydraulic conductivity of $3.7 \times 10^{-3} \mathrm{~m} / \mathrm{s}$ for the sediments of the MGP (section 'Appearance of HF-types in the MGP'). The slightly heightened conductivity value from the evaluation of the pumping tests compared to the results of the HF-analysis can be explained by the presence of BM/OW couplets (Dann et al. 2008; Burbery et al. 2018). Highly permeable layers generally affect the abstraction rate in pumping experiments disproportionately positively in comparison to their volume proportion, and even small layers of OW gravels importantly influence computed hydraulic conductivity (Fogg and Zhang 2016). The ratio of horizontal to vertical hydraulic conductivity from 10:1, well known for fluvioglacial aquifers, can be explained by the observed dominance of the horizontally deposited HFtypes $\mathrm{Gcm}$ and $\mathrm{Gmm}$ by $80.2 \%$ (Hölting and Coldewey 2013). On the other hand, in the crossbedded BM/OW couplets, mixing processes can occur more easily (Huber and Huggenberger 2016).

The overall small-size HF-types occurring in MGP show a very small-scale heterogeneity with large sharp transitions in hydraulic conductivity (Fig. 2). However, in order to explain the intrinsically high variability of hydraulic conductivity $\left(\sigma_{\operatorname{lnK}}^{2}=8.33\right)$, which could be seen in the pumping test, the mere consideration of the HF-types is not sufficient. As standard pumping tests cannot resolve such small-scale heterogeneity, the effect of discharge types on hydraulics must be considered. Discharge types highlight the dependence of the arrangement and the correlation lengths of HF-types, and especially of the BM/OW couplets, on runoff dynamics and paleo-topography rather than randomly distributed in fluvioglacial sediments (Huber and Huggenberger 2015). The estimated values of the three discharge types for hydraulic conductivity cover a wide range of results from the pumping tests (Fig. 8). Since all but one of the outcrops are composed of several discharge types, it is not surprising at all that the hydraulic conductivity values in the MGP can differ widely.
Fig. 8 Histogram of the hydraulic conductivity values from the pumping test evaluation. The estimated hydraulic conductivity range is highlighted in color. The interval of the main discharge type was estimated to be greater due to being associated with more permeable deposits

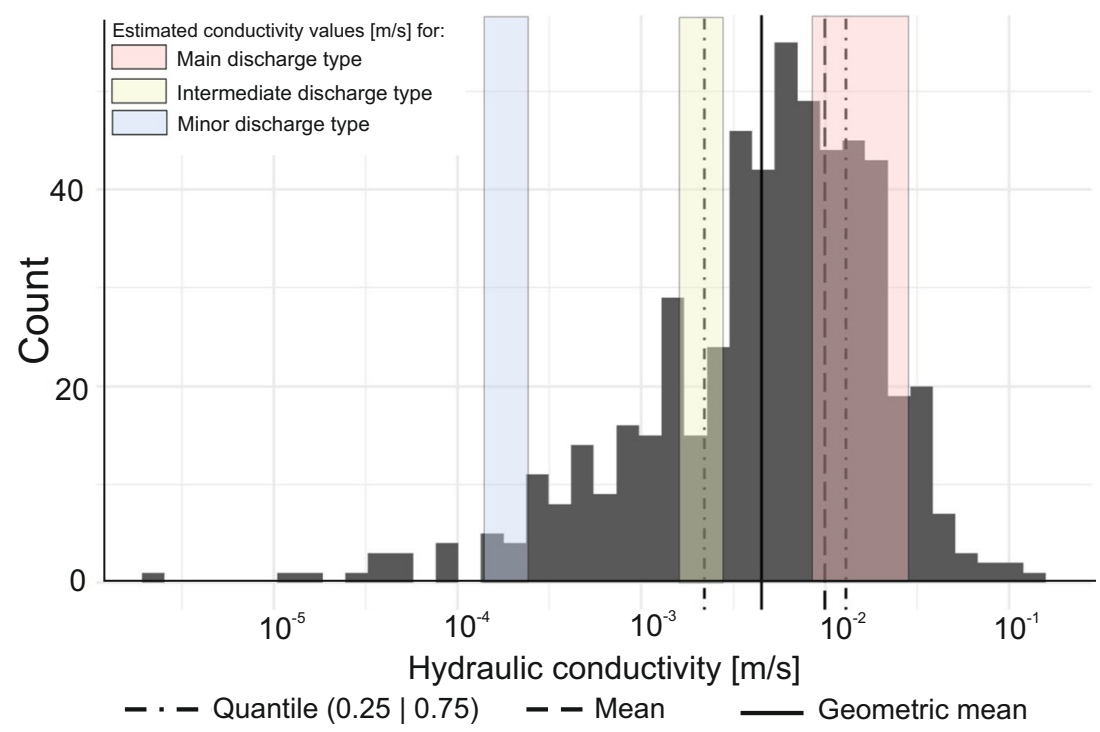


Based on the parameterization of the HF-analysis in the main discharge type, values of the hydraulic conductivity around $9.1 \times 10^{-3} \mathrm{~m} / \mathrm{s}$ can also be explained in a facial way (section 'Appearance of HF-types in the MGP). However, it is also quite conceivable that, due to further effects, the significantly higher conductivity values $(>0.01 \mathrm{~m} / \mathrm{s})$ also occur on account of main discharge type (Fig. 8). The already strong connectivity of the BM/OW couplets in the main discharge type is strengthened by the frequent occurrence of the lithofacies type $\mathrm{Gcm}$,a, which contains thin-layer, matrixfree OW gravels. Burbery et al. (2018) shows that this kind of lithofacies type can also contribute to the connectivity of the OW gravels. Due to the connectivity of the BM/OW couplets in the main discharge types, local areas of high conductivity are built, in which high groundwater fluxes and transport rates can be expected. It was assumed that especially the connectivity of the individual $\mathrm{BM} / \mathrm{OW}$ couplets and the lithofacies-type $\mathrm{Gcm}$, a can lead to higher values in the hydraulic conductivity than would be estimated from the HF-analysis. These local positive anomalies could also be found in the evaluation of the pumping tests in the MGP , which differ from the bulk conductivity by up to two orders of magnitude (Fig. 8). Also, Heinz et al. (2003) revealed the effects of the main discharge types on groundwater flow by performing particle tracing modelling for each discharge type. Compared to the other discharge type, transport through the main discharge type took less than half the time. Furthermore, the small size of the main discharge types from 20 to $50 \mathrm{~m}$ horizontal extent shows that these good sediment properties can only be correlated at a very small distance (section 'Appearance of HF-types in the MGP).

By means of intermediate and minor discharge types, low and medium ranges can be derived from the distribution of hydraulic conductivity values in fluvioglacial outwash plains (Fig. 8). However, a greater variance in hydraulic conductivity is to be expected in the intermediate type, since the HF-types $\mathrm{Gmm}, \mathrm{Gcm}$ and $\mathrm{BM} / \mathrm{OW}$ have similar proportions, resulting in many small-scale facies changes with sharp transitions in hydraulic properties. These contribute to various mean values in standard pumping tests, but are much more decisive for transport processes in the aquifer. A distinction between the intermediate type and the minor type cannot be easily made in pumping tests. Modeling of the mean residence time of particle transport also resulted in small time differences between sediments of the intermediate and minor discharge types (Heinz et al. 2003). Due to the low spread of the main discharge type $(20-50 \mathrm{~m})$ compared to the other two $(>100 \mathrm{~m})$, it can be assumed that higher values have a smaller spatial correlation than lower values. Based on this short correlation length, at least high hydraulic conductivity values can be regarded as very local and the assumption can be made that they cannot be interpolated across larger areas or between locations with greater distance.

With a growing model size, also the question of underlying trends is of great importance for larger model sizes to ensure that the assumptions made are valid throughout the model area. The transition from the proximal depositional area in the south to the medial depositional area in the north is only indicated in the matrix composition and the degree of sorting of the depositional elements (HFtype Gmm and Gcm; section 'Regional trends'). The occurrence of the sandier pronounced lithofacies type Gsm in the northernmost outcrops may indicate the transition to the medial fan sedimentation (Zieliński and van Loon 2000). In the medial fan area, an enhanced hydraulic conductivity can be expected due to a higher sand share and the absence of fine material in the matrix of accretionary elements types (here: HF-type Gcm; Bowman 2019). This assumption is confirmed by the slight increase in hydraulic conductivity of the northernmost part of the MGP (Fig. 4). Apart from this northern boundary area, however, there is no change in hydraulic conductivity in the downward direction that could be detected in the pumping test evaluations. The differences in hydraulic properties between the two HF-types $\mathrm{Gmm}$ and $\mathrm{Gcm}$ are too small compared to the contrast caused by the occurrence of BM/OW couplings.

The results of the work provide important conclusions about sediment structures, which have a great influence on the hydraulics in the aquifer. Especially, the different correlation of high and low conductivity values is highlighted, which can contribute to an improved understanding of the calibration of groundwater models. In addition, the results of facies analyses are already widely used today to improve groundwater predictions with the help of geological models, especially if the transfer of HF units to drilling descriptions is successful (Comunian et al. 2011). Furthermore, the data of the HFanalysis in the MGP give no evidence of nonstationarity in the hydraulic conductivity distribution on a regional model scale, which is an important input for stochastic facies models.

However, HF-analysis is also subject to uncertainties, which can lead to false results. On the one hand, these lie in the methods itself. Misinterpretations cannot be ruled out. However, since the hydraulically most relevant unit (BM/ OW) differs from the other HF-types $(\mathrm{Gcm} / \mathrm{Gmm})$ due to cross-layering, alternating sequence and concave boundaries, the influence here is not very high. Furthermore, there are uncertainties in the parameterization of the hydraulic properties of the HF-types. The parameters were taken from older research work and determined from undisturbed pores $(\mathrm{Gmm}$, $\mathrm{Gcm})$ and disturbed samples (BM/OW) by means of a Darcy experiment (Jussel et al. 1994; Heinz et al. 2003). The standard deviation in such experiments is usually $25-35 \%$ (Storz et al. 2017). A further disadvantage results from the fact that in 
situ sampling is not possible. The results obtained from the unsaturated zone must be transferred to the aquifer material. In the northern outcrops, where the unsaturated-zone and aquifer thickness are only a few meters each, this disadvantage is less significant than in the south, where both the unsaturated-zone and aquifer thickness can increase to a few tens of meters. In the south this is invalidated because the gravel pits have higher outcrop walls, but the unobservable part is still larger and extends a few meters (Fig. 1). Due to the fact that there were no significant trends observed in the downfan direction or vertical direction in the MGP, nor any observable trends from drilling data, it is believed that the observations from the unsaturated zone can be transferred to the aquifer; however, processes such as cementation and compaction of the sediment material were not considered.

\section{Transferability of the results to comparable environmental systems}

Since sedimentological recording is time-consuming and data from HF-analyses of fluvioglacial systems are not yet sufficiently published in research, the question arises to what extent the results are transferable to comparable environmental systems. In the following, special attention is paid to correlation lengths and spatial trends.

\section{Discharge types and correlation lengths of BM/OW couplets}

Discharge types are mainly described in research on outwash plains. Heinz and Aigner (2003b) introduced the terms on the basis of studies on the fluvioglacial Rhine gravels of southwestern Germany. The measured correlation lengths of BM/OW couplets tend to be a bit larger than those observed in the MGP, but reproduce the same trend (Heinz and Aigner 2003b). Observations of massive channel structures (coarse- grained, crossed sets) in the proximal areas of Pleistocene fans in Poland (GP elements, facies association P1, Zielinski and van Loon 2003) indicate the probable existence of even larger highly permeable main flow types also in other fluvioglacial sand plains, especially in the area next to the former ice sheet margin. Such sedimentary compounds, which show excellent hydraulic conditions, can be assumed to exist in the areas of the present receiving waters (Amper, Würm, Isar) of the MGP or in areas where deep channels have cut into the base of the aquifer.

In braided river systems, which do not form an outwash plain, no subdivision according to discharge types is made. Due to the constriction caused by the surrounding topography, the deposited material is repeatedly reprocessed. This results in the formation of hardly any minor discharge types. With large braided river systems, however, a distinction can be made between active and inactive areas (Huber and Huggenberger 2015). The correlation lengths of $\mathrm{BM} / \mathrm{OW}$ couplets observed here are comparable with those from the main outflow type in outwash gravel plains (Table 2). The mapping from georeferenced photos in confined valleys in Switzerland resulted in correlation lengths, which correspond to the correlation lengths from the main discharge types in MGP (Jussel et al. 1994). Further investigations on BM/ OW couplings in Switzerland led to significantly greater results for the correlation lengths in braided river systems, but this is also due to the imaging method with ground penetration radar (GPR) (Beres et al. 1999). A comparison of outcrop analysis performed with outcrop photography and with GPR is shown in Kostic and Aigner (2007). The results of GPR measurements are comparable to the lengths of stacked BM/OW couplets (Fig. 6). The overall longer correlation lengths in valley confined braided river systems suggest that higher values for hydraulic conductivity can also be expected in the fluvioglacial deposits of

Table 2 Overview different measurements of stacked BM/OW couplets in comparable deposition systems in comparable studies

\begin{tabular}{llllll}
\hline Publication & Length $[\mathrm{m}]$ & Height $[\mathrm{m}]$ & Depositional system & Geomorphological setting & Method \\
\hline Jussel et al. (1994) & 11.1 (mean) & 0.48 & Braided river system & Valley with parallel boundaries & Sketches, photos \\
Beres et al. (1999) & $20-41$ & 2 & Braided river system & Valley & GPR \\
Kostic and Aigner (2007) & A few meters & $0.5-1$ & Gravel-bed river & Confluence zones & Sketches, photos \\
Heinz and Aigner (2003b) & $10-30$ (type A) & $1-3$ & Braided river system & Outwash plains & GPR \\
& 7-30 (type B) & $0.7-0.8$ & & Outwash plains & GPR \\
& 2-18 (type C) & $0.3-0.6$ & & Outwash plains & GPR \\
\hline
\end{tabular}

$G P R$ ground penetration radar 
confined valleys compared to the MGP. In the peripheral areas of the MGP, where ascending topography constrain the MGP, slightly increased values for hydraulic conductivity can also be found in the MGP (Fig. 4a).

A trend toward larger scour fills in the downcurrent direction, as described by Siegenthaler et al. (1993) or in Ventra and Clarke (2018), could not be deduced from these investigations, due to the strong influence of the discharge type. However, if the study site is in a braided river system, the size of the BM/OW couplets can depend on the transport distance and should thus be considered.

\section{Regional trends}

The transition from a proximal area dominated by the less permeable HF-type Gmm can be observed in MGP only in the composition of the depositional elements (HF-types $\mathrm{Gmm}$ and $\mathrm{Gcm}$ ) and exhibits no hydraulic effects. Compared to this, stronger trends could be observed in other works on outwash plains. Downfan trends in the form of grain size reduction or shifts in facies association are often described in different models of outwash plains (McDonald and Banerjee 1971; Boothroyd and Ashley 1975; Rust 1978). Although a decrease in the largest particle size can be observed in the MGP, this does not lead to an altered composition of the HF-types as described in Zielinski and van Loon (2003), which should lead to a noticeable change in the average hydraulic conductivity. Wide areas of the MGP correspond to proximal fan sedimentation, with gravel as the dominant grain size. In proximal fans, the mass-flow processes and unchannelized transport dominate (Zieliński and van Loon 2000). The high proportion of accretionary elements found in the MGP confirms this. Moreover, individual deeper channel systems can develop. According to Bowman (2019), the highest values for hydraulic conductivity are found in the medial region, which is only indicated in the northernmost foothills of the MGP.

Reasons for the weak spatial trend and the hardly pronounced facies change in the MGP are seen in the surrounding topography. In the distal areas of the MGP, different fans of the outwash plain are distracted by the protruded hills of the Tertiary hilly landscape. The distal area narrowing can explain the weak downcurrent trend in the hydrofacies distribution. This effect is strengthened by a slight, constant gradient of the erosive top of the subjacent sediments $(1-2 \%$ ) of the fluvioglacial sediments, caused by changes from more erodible sandy and silty sublayered material in the proximal and middle part of the MGP to harder erodible, sublayered gravel in the distal areas of the MGP (Schäfer 1968). In contrast, modern-day sandar extends a shorter distance in the downcurrent direction between the glacier margin and the sea, and widens in distal patterns, resulting in a rapid decrease in current energy and finally sedimentation of a finer (sandy) grain size (Zielinski and van Loon 2002).

\section{Conclusion}

The sediments of fluvioglacial outwash plains have, on the one hand, a high average hydraulic conductivity, but on the other hand have also a wide variability in conductivity values. Sedimentological analyses in the Munich gravel plain could show that reoccurring depositional forms, so-called discharge types, lead to this strong heterogeneity. Closely related highly permeable HF-types can enhance this effect in the main discharge type. The sediment records also indicate that sediments with high conductivity values measured in pumping tests are assigned a significantly smaller correlation length than sediments with lower conductivity values. This is an important finding for hydrogeological investigation such as the parameterization of groundwater models. In most cases, the hydraulically relevant BM/ OW couplets occur individually and in small sizes $(2.5 \mathrm{~m}$ in the horizontal direction and up to $0.5 \mathrm{~m}$ in the vertical direction). For the main discharge, however, the BM/OW couplets can appear stacked and form highly permeable bodies averaging $12 \mathrm{~m}$ in horizontal length and up to $50 \mathrm{~m}$ in width. Furthermore, no spatial trend can be identified in the MGP deposits. The results of the distribution of the HF-types and the correlation lengths seem to be well transferable to other fluvioglacial systems. However, the influence of regional trends depends strongly on the surrounding topography and must be checked individually.

Acknowledgements We thank Veronika Hillebrand and Dr. Nickmann for their support in the geotechnical laboratory. We would like to thank Philipp Siebert and Regina Stöger for their help in developing the classification scheme of the pumping test evaluations. Furthermore, we thank an anonymous reviewer for useful comments regarding the language and clarity of the script.

Funding information Open Access funding provided by Projekt DEAL. This study was funded by the Bavarian Geological Survey. 


\section{Appendix}

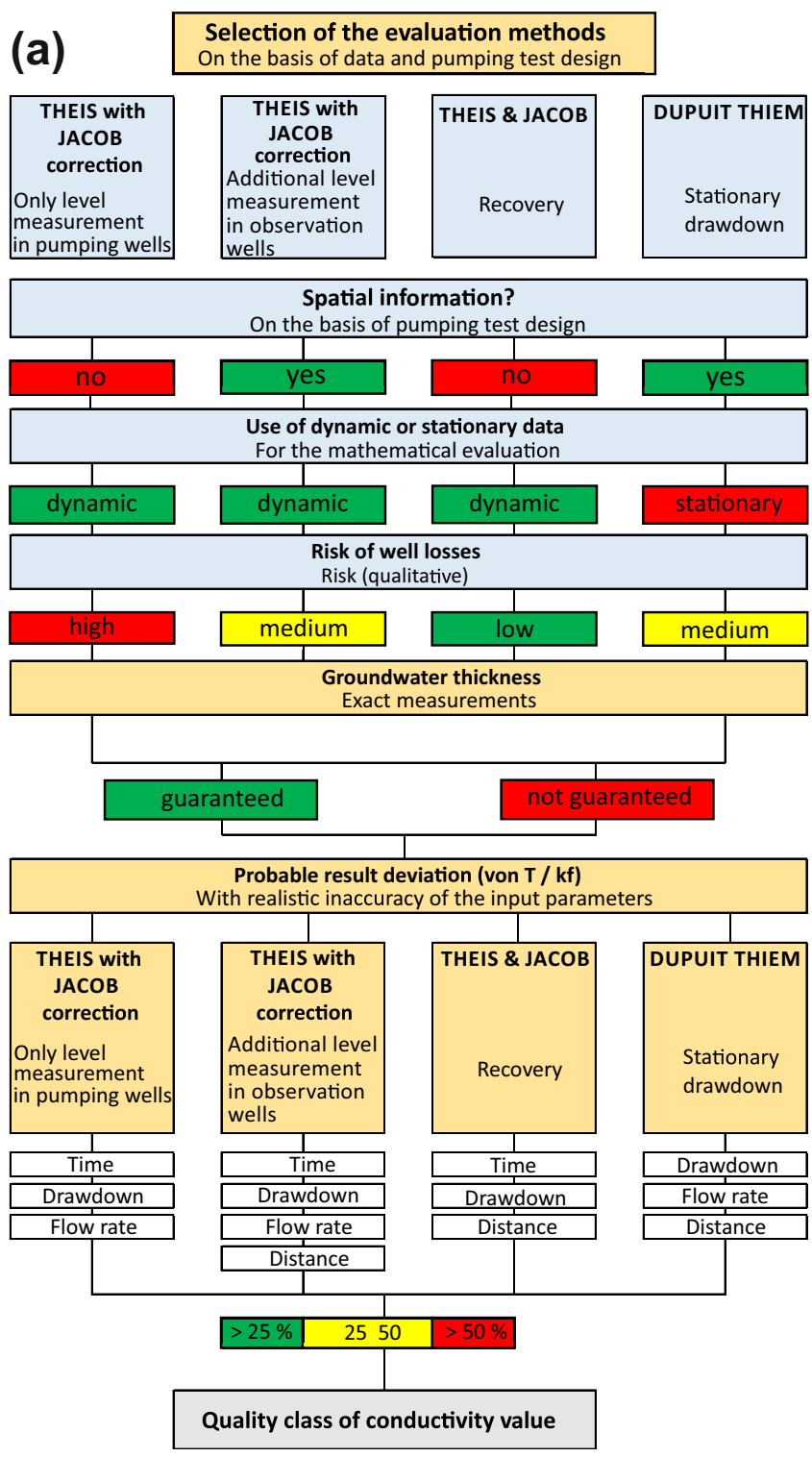

Fig. 9 a The classification scheme for evaluating a pumping test. It considers the properties of the evaluation method, the aquifer data and the data quality of the reports. b Shows the application of the scheme and how to find out the quality class by simple query. If the questions

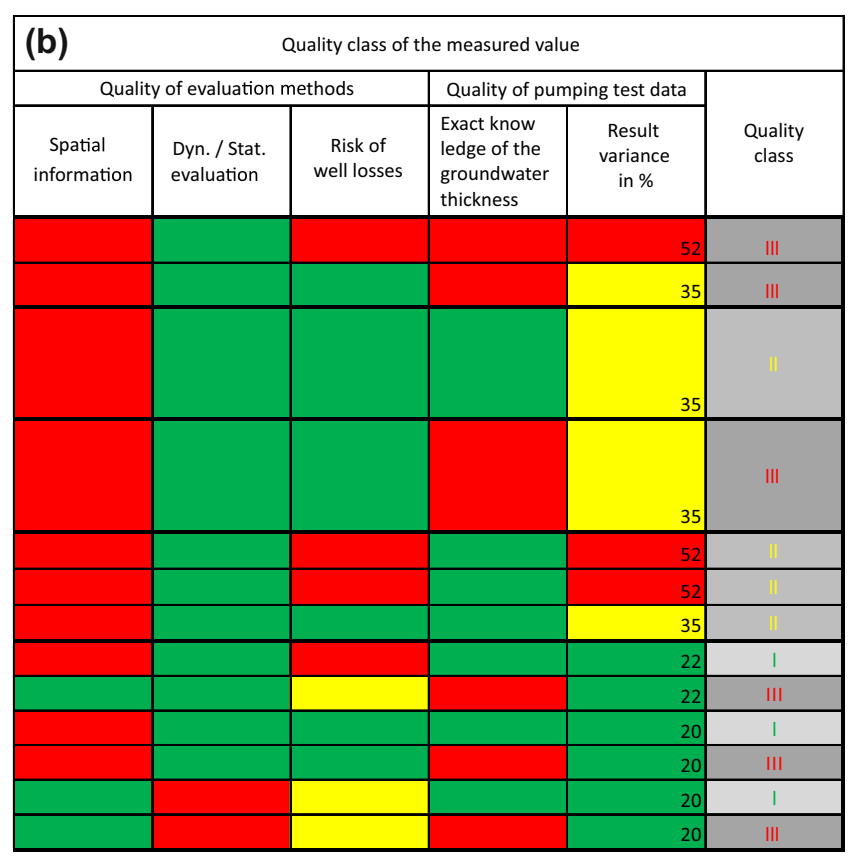

according to the classification scheme (a) lead to a positive influence, the query fields are filled in green, in case of no influence in yellow, and in case of a negative influence in red. Depending on the combination of colors, the quality class is determined 
Open Access This article is licensed under a Creative Commons Attribution 4.0 International License, which permits use, sharing, adaptation, distribution and reproduction in any medium or format, as long as you give appropriate credit to the original author(s) and the source, provide a link to the Creative Commons licence, and indicate if changes were made. The images or other third party material in this article are included in the article's Creative Commons licence, unless indicated otherwise in a credit line to the material. If material is not included in the article's Creative Commons licence and your intended use is not permitted by statutory regulation or exceeds the permitted use, you will need to obtain permission directly from the copyright holder. To view a copy of this licence, visit http://creativecommons.org/licenses/by/4.0/.

\section{References}

Albarrán-Ordás A, Zosseder K (2020) Geostatistical relief modelling of the quaternary aquifer basis in the Munich gravel plain with the use of big datasets. zdgg 171(1):S.1-S.19. https://doi.org/10.1127/zdgg/ 2020/0206

Ashmore P (2017) Channel morphology and bed load pulses in braided, gravel-bed streams. Geograf Annaler: Ser A, Physical Geogr 73(1): 37-52. https://doi.org/10.1080/04353676.1991.11880331

Bakshevskaya VA, Pozdnyakov SP (2013) Methods of modeling hydraulic heterogeneity of sedimentary formations. Water Res 40(7):767775. https://doi.org/10.1134/S0097807813070026

Bauer M, Kurosch T, Scholz M, and Neumann P (2005) The geology of Munich (Germany) and its significance for ground modelling in urban areas. Geotechnik. 28(2)

Bayer P, Comunian A, Höyng D, Mariethoz G (2015) High resolution multi-facies realizations of sedimentary reservoir and aquifer analogs. Scientific Data 2, 150033 EP

Bennett JP, Haslauer CP, Cirpka OA (2017) The impact of sedimentary anisotropy on solute mixing in stacked scour-pool structures. Water Resour Res 53(4):2813-2832. https://doi.org/10.1002/ 2016WR019665

Beres M, Huggenberger P, Green AG, Horstmeyer H (1999) Using twoand three-dimensional georadar methods to characterize glaciofluvial architecture. Sediment Geol 129(1-2):1-24. https:// doi.org/10.1016/S0037-0738(99)00053-6

Best J, Fielding CR (2019) Describing fluvial systems: linking processes to deposits and stratigraphy. Geol Soc Lond Spec Publ 1, SP4882019-056. https://doi.org/10.1144/SP488-2019-056

Bianchi M, Kearsey T, Kingdon A (2015) Integrating deterministic lithostratigraphic models in stochastic realizations of subsurface heterogeneity: impact on predictions of lithology, hydraulic heads and groundwater fluxes. J Hydrol 531(S):557-573. https://doi.org/10. 1016/j.jhydrol.2015.10.072

Blasy L (1974) Die Grundwasserverhältnisse in der Münchener Schotterebene westlich der Isar [The groundwater conditions in the Munich gravel plain west of the Isar]. PhD Thesis, Technische Universität München, München, Germany

Boothroyd JC, Ashley GM (1975) Processes, bar morphology, and sedimentary structures on braided outwash fans, Northeastern Gulf of Alaska: glaciofluvial and glaciolacustrine sedimentation. Soc Econ Paleontol Mineral Spec Publ 23:193-222. https://doi.org/10.2110/ pec.75.23.0193

Böttcher F, Casasso A, Götzl G, Zosseder K (2019) TAP - thermal aquifer potential: a quantitative method to assess the spatial potential for the thermal use of groundwater. Renew Energy 142:85-95. https://doi. org/10.1016/j.renene.2019.04.086

Bowman D (2019) Principles of alluvial fan morphology. Springer Netherlands, Dordrecht, The Netherlands, $5 \mathrm{pp}$
Burbery LF, Moore CR, Jones MA, Abraham PM, Humphries BL, Close ME (2018) Study of connectivity of open framework gravel facies in the Canterbury Plains aquifer using smoke as a tracer. Geol Soc Lond Spec Publ 440(1):327-344. https://doi.org/10.1144/SP440.10

Comunian A, Renard P, Straubhaar J, Bayer P (2011) Three-dimensional high resolution fluvio-glacial aquifer analog, part 2: geostatistical modeling. J Hydrol 405(1-2):10-23. https://doi.org/10.1016/j. jhydrol.2011.03.037

Dann RL, Close ME, Pang L, Flintoft MJ, Hector RP (2008) Complementary use of tracer and pumping tests to characterize a heterogeneous channelized aquifer system in New Zealand. Hydrogeol J 16(6):1177-1191. https://doi.org/10.1007/s10040-008-0291-4

Dohr F, Gruban W (1999) Grundwasser-Überwachungssystem der Landeshauptstadt München: Abschlussbericht [Groundwater monitoring system of the city of Munich: Final report]. Landeshauptstadt München, Munich, Germany

Doppler G, Kroemer E, Rögner K, Wallner J, Jerz H, Grottenthaler W (2011) Quaternary stratigraphy of southern Bavaria. E\&G - Quatern Sci J 60(2-3):329-365. https://doi.org/10.3285/eg.60.2-3.08

Exler HJ (1967) Hydrogeologische Profile der U-Bahn-Trasse zwischen Haupt-und Ostbahnhof der Landeshauptstadt München [Hydrogeological profiles of the underground railway line between the main and eastern railway stations of the City of Munich]. Deutsche Gewässerkundliche Mitteilungen 1967 (Sonderheft), pp 101-111

Fetter CW (2001) Applied hydrogeology, 4th edn. Prentice Hall, Upper Saddle River, NJ

Fogg GE, Zhang Y (2016) Debates-stochastic subsurface hydrology from theory to practice: a geologic perspective. Water Resour Res 52(12): 9235-9245. https://doi.org/10.1002/2016WR019699

Freudenberger W, Schwerd K (1996) Erläuterungen zur Geologischen Karte von Bayern 1: 500000 [Explantations of the Geological Map of Bavaria 1: 500 000], 4th Edition. Bayerisches Geologisches Landesamt, München, Germany

Gebhardt P (1968) Die geologischen und hydrogeologischen Verhältnisse beim Münchner U-Bahn-Bau [The geological and hydrogeological conditions at the Munich underground railway construction]. $\mathrm{PhD}$ Thesis, Ludwig-Maximilians Universität, Munich, Germany

Górska-Zabielska M (2008) Conditions of sedimentation in the Weichselian glaciomarginal zone of northeastern Germany. Geol Q 52:157-168

Grottenthaler W (1980) Geologische Karte von Bayern 1:25 000: Erläuterungen zum Blatt Nr.7833 [Geological map of Bavaria 1:25 000: explanations to sheet no. 7833 ]. Fürstenfeldbruck, Munich, Germany

Heinz J, Aigner T (2003a) Hierarchical dynamic stratigraphy in various quaternary gravel deposits, Rhine glacier area (SW Germany): implications for hydrostratigraphy. Int J Earth Sci 92(6):923-938. https://doi.org/10.1007/s00531-003-0359-2

Heinz J, Aigner T (2003b) Three-dimensional GPR analysis of various quaternary gravel-bed braided river deposits (southwestern Germany). Geol Soc Lond Spec Publ 211(1):99-110. https://doi. org/10.1144/GSL.SP.2001.211.01.09

Heinz J, Kleineidam S, Teutsch G, Aigner T (2003) Heterogeneity patterns of quaternary glaciofluvial gravel bodies (SW-Germany): application to hydrogeology. Sediment Geol 158(1-2):1-23. https:// doi.org/10.1016/S0037-0738(02)00239-7

Hölting, Bernward; Coldewey, Wilhelm Georg (2013) Hydrogeologie: Einführung in die Allgemeine und Angewandte Hydrogeologie [Hydrogeology: introduction to general and applied hydrogeology, 8th edn.]. Spektrum Akademischer Verlag, Heidelberg, Germany

Huber E, Huggenberger P (2015) Morphological perspective on the sedimentary characteristics of a coarse, braided reach: Tagliamento River (NE Italy). Geomorphology 248:111-124. https://doi.org/10. 1016/j.geomorph.2015.07.015

Huber E, Huggenberger P (2016) Subsurface flow mixing in coarse, braided river deposits. Hydrol Earth Syst Sci 20(5):2035-2046. https://doi.org/10.5194/hess-20-2035-2016 
Huggenberger P, Epting J (2011) Urban geology. https://doi.org/10.1007/ 978-3-0348-0185-0

Huggenberger P, Regli C (2006) A sedimentological model to characterize Braided River deposits for hydrogeological applications. In: Sambrook Smith GH (ed) Braided rivers: process, deposits, ecology and management. Blackwell, Malden, MA, pp 51-74

Isaaks EH, Srivastava RM (1989) Applied geostatistics. Oxford Univ. Press, New York, $561 \mathrm{pp}$

Jussel P, Stauffer F, Dracos T (1994) Transport modeling in heterogeneous aquifers: 1 . statistical description and numerical generation of gravel deposits. Water Resour Res 30(6):1803-1817. https://doi. org/10.1029/94WR00162

Kearsey T, Williams J, Finlayson A, Williamson P, Dobbs M, Marchant B et al (2015) Testing the application and limitation of stochastic simulations to predict the lithology of glacial and fluvial deposits in central Glasgow, UK. Eng Geol 187:98-112. https://doi.org/10. 1016/j.enggeo.2014.12.017

Kerl M, Runge N, Tauchmann H, Goldscheider N (2012) Conceptual hydrogeological model of the city of Munich, Germany, as a basis for geothermal groundwater utilisation. Grundwasser 17(3):127135. https://doi.org/10.1007/s00767-012-0199-8

Klingbeil R, Kleineidam S, Asprion U, Aigner T, Teutsch G, Aigner T (1999) Relating lithofacies to hydrofacies: outcrop-based hydrogeological characterisation of Quaternary gravel deposits. Sediment Geol 129(3-4):299-310. https://doi.org/10.1016/S00370738(99)00067-6

Kostic B, Aigner T (2007) Sedimentary architecture and 3D groundpenetrating radar analysis of gravelly meandering river deposits (Neckar Valley, SW Germany). Sedimentology 54(4):789-808. https://doi.org/10.1111/j.1365-3091.2007.00860.x

Lemcke K (1988) Geologie von Bayern: I. Das bayerische Alpenvorland vor der Eiszeit. Erdgeschichte - Bau - Bodenschätze [Geology of Bavaria: I. The Bavarian Alpine foothills before the Ice Age. Earth history - Construction - Mineral resources]. Schweizerbart, Stuttgart, Germany, $175 \mathrm{pp}$

Mahrla HH (1982) Zum Porenraum injizierter Lockersedimente des Münchner Baugrundes [Pore space of injected sediments of the Munich subsoil]. PhD Thesis, Ludwig-Maximilians Universität, Munich, Germany

McDonald BC, Banerjee I (1971) Sediments and bed forms on a braided outwash plain. Can J Earth Sci 8(10):1282-1301. https://doi.org/10. 1139/e 71-116

Miall AD (1985) Architectural-element analysis: a new method of facies analysis applied to fluvial deposits. Earth Sci Rev 22:261-308

Miall AD (2006) The geology of fluvial deposits: sedimentary facies, basin analysis, and petroleum geology, 4th edn. Springer, Berlin

Penck A, Brückner E (1909) Die Alpen im Eiszeitalter [The Alps in the Ice Age]. Tauchnitz, Leipzig, Germany

Pyrcz MJ, Deutsch CV (2014) Geostatistical reservoir modeling, 2nd edn. Oxford University Press, New York, 449 pp)

Rust BR (1978) Depositional model for braided alluvium. In: Miall AD (ed) Fluvial sedimentology, vol 5. Canadian Society of Petroleum Geologists, Calgary, AB, pp 441-444

Sanchez-Vila X, Fernàndez-Garcia D (2016) Debates-stochastic subsurface hydrology from theory to practice: why stochastic modeling has not yet permeated into practitioners? Water Resour Res 52(12): 9246-9258. https://doi.org/10.1002/2016WR019302

Schäfer I (1968) Münchner Ebene und Isartal: Ein Beitrag zur Frage der Entstehung [Munich plain and the Isar valley: a contribution to the question of origin]. Mitteil Geograph Gesellsch München 1968:175-203

Schaefer I (1978) Die Gliederung der Münchener Ebene: Eine geomorphologische Analyse [the structure of the Munich plain: a geomorphological analysis]. Mitteil Geograph Gesellsch München 63:37-67

Schirm E (1968) Die hydrogeologischen Verhältnisse der Münchener Schotterebene östlich der Isar: Beitrag zur hydrologischen Dekade der UNESCO [The hydrogeological conditions of the Munich gravel plain on the east of the Isar river: contribution to the UNESCO hydrological decade]. Bayerische Landesstelle für Gewässerkunde, Munich, Germany

Siegenthaler C, Huggenberger P, Sambrook Smith G, Best J, Bristow C, Petts G (1993) Pleistocene Rhine gravel: deposits of a braided river system with dominant pool preservation. In: Braided Rivers: where have we come in 10 years? Progress and future needs. International Association of Sedimentologists, pp 142-162. https://doi.org/10. 1002/9781444304374.ch1

Slomka JM, MacCormack KE, Eyles CH (2019) Preservation of local high-resolution data in a regional low-resolution dataset: a 'nested' 3D modeling approach using an example from a Quaternary glacial stratigraphy (Ontario, Canada). Eng Geol 248:309-329. https://doi. org/10.1016/j.enggeo.2018.12.007

Stauffer F (2007) Impact of highly permeable sediment units with inclined bedding on solute transport in aquifers. Adv Water Resour 30(11): 2194-2201. https://doi.org/10.1016/j.advwatres.2007.04.008

Storz K, Steger H, Wagner V, Bayer P, Blum P (2017) Methodenvergleich zur Bestimmung der hydraulischen Durchlässigkeit [Method comparison for the determination of hydraulic permeability]. Grundwasser 22(2):103-111. https://doi.org/10.1007/s00767-017-0353-4

Theis CV (1935) The relation between the lowering of the piezometric surface and the rate and duration of discharge of a well using groundwater storage. Trans Am Geophys Union (16):519-524

Thiem G (1906) Hydrologische Methoden [Hydrological methods]. Gebhardt, Leipzig, Germany

Todd SP (1989) Stream-driven, high-density gravelly traction carpets: possible deposits in the Trabeg conglomerate formation, SW Ireland and some theoretical considerations of their origin. Sedimentology 36(4):513-530. https://doi.org/10.1111/j.13653091.1989.tb02083.x

Ventra D, Clarke LE (2018) Geology and geomorphology of alluvial and fluvial fans: current progress and research perspectives. Geol Soc Lond Spec Publ 440(1):1-21. https://doi.org/10.1144/SP440.16

Vienken T, Huber E, Kreck M, Huggenberger P, Dietrich P (2017) How to chase a tracer: combining conventional salt tracer testing and direct push electrical conductivity profiling for enhanced aquifer characterization. Adv Water Resour 99:60-66. https://doi.org/10. 1016/j.advwatres.2016.11.010

Vogt N (2006) Raumordnungsunterlagen 3. Start- und Landebahn: Wasserwirtschaft. Government of Oberbayern, Munich, Germany

Zappa G, Bersezio R, Felletti F, Giudici M (2006) Modeling heterogeneity of gravel-sand, braided stream, alluvial aquifers at the facies scale. J Hydrol 325(1-4):134-153. https://doi.org/10.1016/j.jhydrol.2005.10.016

Zhu L, Gong H, Dai Z, Guo G, Teatini P (2017) Modeling 3-D permeability distribution in alluvial fans using facies architecture and geophysical acquisitions. Hydrol Earth Syst Sci 21(2):721-733. https:// doi.org/10.5194/hess-21-721-2017

Zieliński T, van Loon AJ (2000) Subaerial terminoglacial fans III: overview of sedimentary characteristics and depositional model. Netherlands J Geosci - Geol Mijnbouw 79(1):93-107. https://doi. org/10.1017/S0016774600021600

Zielinski T, van Loon AJ (2002) Present-day sandurs are not representative of the geological record. Sediment Geol 152(1-2):1-5. https:// doi.org/10.1016/S0037-0738(02)00231-2

Zielinski T, van Loon A (2003) Pleistocene sandur deposits represent braidplains, not alluvial fans. Boreas 32(4):590-611. https://doi. org/10.1080/03009480310004170

Zimniok K (1967) Die Grundwasserverhältnisse beim U-Bahn-Bau in München. [The groundwater conditions at the underground railway construction in Munich]. Deutsche Gewässerkundliche Mitteilungen (Sonderheft) 94-100, Selbstverlag, Koblenz, Germany 